\title{
Understanding Patterns of Brain Metastasis in Triple-Negative Breast Cancer and Exploring Potential Therapeutic Targets
}

This article was published in the following Dove Press journal: OncoTargets and Therapy

Yan Lv'

Xiao $\mathrm{Ma}^{2}$

Yuxin Du'

Jifeng Feng $\mathbb{D}^{\prime}$

'The Affiliated Cancer Hospital of Nanjing Medical University, Jiangsu Cancer Hospital, Jiangsu Institute of Cancer Research, Nanjing 210009 , People's Republic of China; ${ }^{2}$ Department of General Surgery, The Affiliated Zhongda Hospital of Southeast University, Nanjing 210009, People's Republic of China
Correspondence: Jifeng Feng The Affiliated Cancer Hospital of Nanjing Medical University, Jiangsu Cancer Hospital, Jiangsu Institute of Cancer Research, 42 Baiziting, Nanjing 210009 ,

People's Republic of China

$\mathrm{Tel} / \mathrm{Fax}+8602583283584$

Email jifeng_feng@।63.com

\begin{abstract}
Triple-negative breast cancer (TNBC) is a highly malignant subtype of breast cancer. High invasiveness and heterogeneity, as well as a lack of drug targets, are the main factors leading to poor prognosis. Brain metastasis (BM) is a serious event threatening the life of breast cancer patients, especially those with TNBC. Compared with that for hormone receptor-positive and HER2-positive breast cancers, TNBC-derived BM (TNBCBM) occurs earlier and more frequently, and has a worse prognosis. There is no standard treatment for $\mathrm{BM}$ to date, and one is urgently required. In this review, we discuss the current knowledge regarding the developmental patterns of TNBCBM, focusing on the key events in BM formation. Specifically, we consider (i) the nature and function of TNBC cells; (ii) how TNBC cells cross the blood-brain barrier and form a fenestrated, more permeable bloodtumor barrier; (iii) the biological characteristics of TNBCBM; and (iv) the infiltration and colonization of the central nervous system (CNS) by TNBC cells, including the establishment of premetastatic niches, immunosurveillance escape, and metabolic adaptations. We also discuss putative therapeutic targets and precision therapy with the greatest potential to treat $\mathrm{TNBCBM}$, and summarize the relevant completed and ongoing clinical trials. These findings may provide new insights into the prevention and treatment of BM in TNBC patients.
\end{abstract}

Keywords: triple-negative breast cancer, brain metastasis, blood-brain barrier, blood-tumor barrier, microenvironment, therapeutic targets

\section{Introduction}

Breast cancer is the most frequently diagnosed malignancy and a leading cause of death in women worldwide. ${ }^{1}$ Triple-negative breast cancer (TNBC) is a highly malignant and invasive subtype of breast cancer, and is defined by the lack of estrogen receptor (ER), progesterone receptor (PR), and human epidermal growth factor receptor 2 (HER2/neu) expression. ${ }^{2}$ TNBC accounts for $15 \sim 20 \%$ of all breast cancer and is more common in young women under the age of 40. It has a high recurrence rate, a high potential for metastasis, and a poor clinical prognosis, and is defined as a refractory breast cancer owing to its resistance to treatment. Among all the breast cancer subtypes, TNBC has the highest rate of distant metastasis and is associated with the shortest overall survival (OS). ${ }^{3}$ Despite undergoing surgical resection and adjuvant chemotherapy, half of all primary TNBC patients in whom the tumor is confined to the breast and lymph nodes have a distant recurrence within five years, and are prone to metastasis to the central nervous system (CNS) and internal organs such as the liver, 
bones, the lung. ${ }^{4}$ Once distant metastasis has occurred, the survival time of TNBC patients is greatly shortened.

Metastasis to the brain remains the most intractable issue for patients with metastatic breast cancer. Brain metastasis (BM) formation will not only affect the physical function, independence, personality, quality of life, and selfawareness of the patients but will also greatly increase the mortality rate compared with metastasis to other organs, which can be as high as $80 \%$ within one year. ${ }^{5} \mathrm{BM}$ accounts for most CNS tumors, but the incidence varies depending on the type of primary malignancy ${ }^{6,7}$ (Figure 1). The subtype of primary breast cancer is critical for metastatic behavior and OS. The incidence of BM is as high as $46 \%$ among patients with advanced $\mathrm{TNBC}$, with $14 \%$ presenting with $\mathrm{BM}$ at initial diagnosis of metastatic TNBC, and is significantly higher than that for hormone receptor (HR)-positive and HER2-positive breast cancer. TNBC is associated with high metastatic potential, particularly to the brain. Compared with that for hormone receptor-positive and HER2-positive breast cancers, TNBC-derived BM
(TNBCBM) occurs earlier and is more often accompanied by extracranial systemic lesions. Patients with TNBCBM also have a much shorter survival time, with a median OS of approximately 6 months, ${ }^{8-11}$ and the worst breast cancerspecific survival (BCSS) and OS. ${ }^{12}$

Differences between the intrinsic molecular subtype of the primary breast cancer and matched BM represent a complex problem that merits further investigation. In approximately $20 \%$ of breast cancer patients, differences in receptor expression exist between the primary cancer and the associated BM, with the most significant manifestations being decreased ER and/or PR expression and increased HER 2 expression. About $18 \%$ of TNBC patients gain ER/PR and HER2 expression. This difference in receptor expression may account for the unresponsiveness or resistance of intracranial disease to systemic therapy. ${ }^{13}$ Traditional therapies have very low efficacy in the treatment of TNBCBM. Additionally, most cytotoxic drugs are restricted in their entry into the CNS, and because TNBC is negative for ER and HER2 expression, endocrine

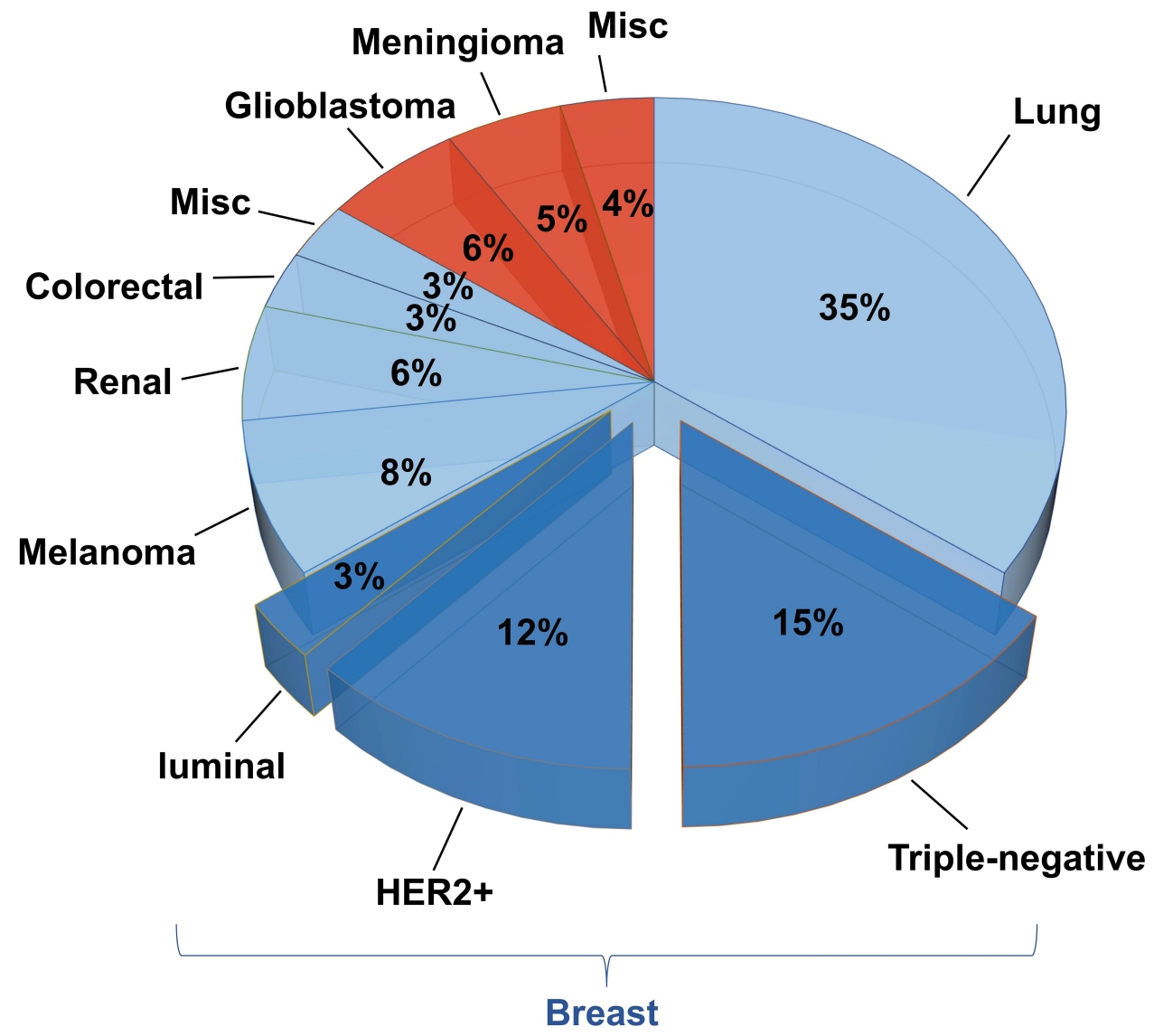

Figure I Proportional etiology of brain metastasis. Of all CNS tumors, 15\% are primary (red), while $85 \%$ are from metastases (blue). The incidence of BM is higher in lung cancer (35\%) and breast cancer (30\%) than other primary cancers. In breast cancer, triple-negative subtypes have the highest rate of BM, followed by HER2+ and luminal subtypes. 
therapy and anti-HER2-targeted therapy are ineffective. Surgical resection of BM is usually limited to isolated metastases, and it is not possible to diagnose the presence of space-occupying lesions in the brain as BM. Consequently, radiotherapy remains the main treatment method for BM. However, the OS is still short even after whole-brain radiotherapy (WBRT) or stereotactic radiotherapy, and patients are prone to brain edema, high intracranial pressure, local brain necrosis, memory and vision loss, and other radiation-related injuries. To date, there are no standard systemic treatments for TNBCBM. Moreover, gene expression patterns in primary TNBCs do not predict the occurrence of BM in this population. ${ }^{11}$ These observations highlight the need to identify potential biomarkers and elucidate the genetic characteristics of patients at high risk of BM to aid in clinical decision-making. Meanwhile, to effectively manage the disease and prolong the survival of TNBCBM patients, it is necessary to better understand the patterns of $\mathrm{BM}$ formation, including the nature and function of TNBC cells and the blood-brain/blood-tumor barriers, the biological characteristics of $\mathrm{BM}$, and the microenvironment of the CNS. In this review, we provide a systematic overview of TNBCBM occurrence and development, as well as of potential therapeutic targets.

\section{TNBC Cells}

TNBC is a subclass of ER-negative breast cancer. Due to the lack of ER expression, it has been generally believed that estrogen signaling is not involved in the occurrence and development of ER-negative breast cancer. However, this is not supported by existing evidence. Wang et al identified and cloned a 36-kDa ER variant, called ER$\alpha 36$, that was mainly localized to the cytoplasm and the plasma membrane. ${ }^{14}$ ER- $\alpha 36$ lacks both the AF-1 and AF2 transcription activation domains of the full-length 66kDa ER- $\alpha$ (ER-66 $\alpha)$ protein but retains the DNA-binding domain and partial dimerization and ligand-binding domains, which is consistent with the fact that ER- $\alpha 36$ has no intrinsic transcriptional activity, but instead mediates nongenomic estrogen signaling. ${ }^{15}$ ER- $\alpha 36$ was found to be highly expressed in TNBC, and knockdown of ERa36 reduced the response of TNBC cells to estrogen. Meanwhile, ER- $\alpha 36$ and EGFR regulated each other's expression through a positive feedback loop in TNBC cells, which promoted their malignant growth. ${ }^{16}$ Studies have also shown that ER- $\alpha 36$ can mediate estrogeninduced cyclin D1 promoter activity through the Scr/ EGFR/STAT5 pathway, leading to increased TNBC cell proliferation. ${ }^{17,18}$ ER- $\alpha 36$ plays an important role in the development and progression of TNBC cells, and may represent a therapeutic target for the treatment of TNBC.

In recent decades, cancer stem cells (CSCs), or cancer stemness, has attracted substantial research interest. CSCs are considered to be a decisive factor in tumor heterogeneity and the leading cause of tumor metastasis and recurrence. TNBC tissue is reported to be enriched for the expression of ALDH1 and the $\mathrm{CD} 44^{+} / \mathrm{CD} 24^{-}$phenotype when compared with other breast cancer subtypes, ${ }^{19,20}$ while TNBC cells are also more likely to form mammospheres than non-TNBC cells. ${ }^{19,21}$ At the transcriptional level, pluripotency-related transcription factors, such as MYC and SOX2, are highly expressed in TNBC and are positively correlated with poor prognosis. ${ }^{22,23} \mathrm{~A}$ recent study found that the gene signature of TNBC cells was remarkably similar to that of CSCs, and the stem cell signature was significantly enriched in TNBC cell lines compared with that in non-TNBC cell lines. ${ }^{24}$ In summary, TNBC cells exhibit CSC characteristics and activity at both the molecular and transcriptional levels.

The epithelial-to-mesenchymal transition (EMT) genetic program is highly associated with cancer cell metastasis. ${ }^{25}$ One study analyzed EMT in circulating tumor cells (CTCs) in breast cancer patients and found that it plays an important role in the blood-borne transmission of breast cancer. ${ }^{26}$ Increasing evidence has indicated that a close relationship exists between TNBC, and EMT and the CSC phenotype. Ectopic overexpression of EMTpromoting transcription factors, such as Snail, Twist, and Zeb1, confers CSCs-like features on mammary epithelial cells, suggesting that EMT may be a key process for the ab initio production of CSCs, and a viable mechanism for the metastatic dissemination of breast tumors. ${ }^{27,28}$ Interestingly, TNBC cells exhibit high expression levels of key EMT-inducing transcription factors, concomitant with increased levels of mesenchymal-related proteins, and reduce expression of epithelial-associated proteins. ${ }^{29}$ Additionally, mesenchymal phenotypes are mainly responsible for the invasive and chemoresistant properties of TNBC cells. ${ }^{30,31}$ TNBC-associated EMT not only includes acquiring migratory and invasive ability, but also involves the complex reprogramming of cells to allow their adaptation to the harsh conditions of the body and facilitate invasion and metastasis. Epigenetic changes differ significantly between TNBC and non-TNBC tissues, including those associated with long noncoding RNAs (lncRNAs), microRNAs (miRNAs), and histone and DNA 
modifications. Studying these changes holds promise for the development of new treatments and the identification of EMT-related biomarkers. ${ }^{32}$ Leptin, a key factor in obesity, is also known to be a risk factor for breast cancer, including TNBC. Leptin can promote a CSC/EMT phenotype and upregulate the expression of multiple CSC-/EMTrelated genes, including FOXC2, TWIST2, VIM, AKT3 and $S O X 2$. Increased leptin signaling is causally associated with obesity-related TNBC through promoting CSC enrichment and EMT. ${ }^{33}$

Multiple self-renewal signaling pathways (SRSPs) have been reported to be abnormally activated in TNBC cells, such as those associated with the signal transducer and activator of transcription (STAT), protooncogene tyrosine-protein kinase Src (SRC), and Wnt/ $\beta$-catenin pathways. The dysregulation of SRSPs leads to a loss of regulatory balance through both intrinsic and extrinsic mechanisms, which helps the widespread dissemination of TNBC cells. Inhibiting aberrantly activated SRSPs to reduce stemness has been shown to exert a therapeutic effect on TNBC to a certain extent. ${ }^{24,34}$

Early maturation and/or a higher expression of elements associated with inflammation and aging in TNBC patients are often observed in the early invasion of TNBC cells. The inhibition of nuclear factor kappa B (NF-kB), a marker of the inflammatory response, can reduce the proliferative and invasive ability of TNBC cells. ${ }^{35}$ Adenosine plays an important role in inflammation and tumor development. The expression of adenosine $\mathrm{A} 2 \mathrm{~b}$ receptor (ADORA2B) is higher in TNBC cells than in luminal and HER2-positive breast cancer, and ADORA2B may drive cancer metastasis by reducing cell adhesion and MAPK-dependent signaling activation. The knockout of ADORA2B in TNBC cells reduces their metastasis in vivo as well as their viability and colonyforming ability. ${ }^{36}$ Telomerase, which is closely related to aging, plays a key role in tumor development, and most tumors achieve proliferative immortality by activating telomeres. Telomere shortening is more pronounced in more aggressive breast cancer subtypes, especially TNBC. ${ }^{37}$

\section{The Blood-Brain Barrier (BBB)}

The BBB is a complex structure formed by brain endothelial cells (BECs), pericytes, and astrocyte foot processes. The BBB is a highly selective barrier between the circulating blood and the brain parenchyma, and is necessary to maintain brain homeostasis. The passage of cells and solutes through the BBB is limited by their molecular weight and charge. ${ }^{38}$ The BBB selectively regulates substances entering the brain and protects it from toxic substances, including chemicals and targeted drugs. Tight junction (TJ) proteins are characteristic of BECs and restrict the paracellular diffusion of substances between the blood and the brain (Figure 2). Brain capillaries are characterized by high electrical resistance that increases the impermeability of the BBB to polar and ionic substrates. Damage to TJs can lead to a leaky BBB and the continuous exposure of the CNS to harmful substances in the circulation. Additionally, changes in intracellular transport in BECs contribute to BBB disruption and disease progression. ${ }^{39}$

The occurrence of $\mathrm{BM}$ requires that tumor cells cross the BBB. The BBB plays a dual role in cancer cell BM, both forming a tight barrier to protect the CNS from invading tumor cells, while also protecting metastatic cells during extravasation and proliferation in the brain. ${ }^{40}$ The loss of BBB integrity due to neuroinflammation, upregulation of proteolytic enzymes, and direct destruction by TNBC cells may promote metastatic invasion. ${ }^{41}$ The partial destruction of the BBB leads to increased invasion of tumor cells and related molecules, thereby potentially promoting tumor cell brain colonization. When tumor cells enter the brain, they mainly gather at the branching points of cerebral vessels and further exude and invade. ${ }^{42}$ Metastatic tumor cells interact with BECs through surface molecules, including selectins, integrins, and chemokines. This is accompanied by the secretion of growth factors such as vascular endothelial growth factor (VEGF), neuropeptide, chemokines and cyclooxygenase 2 (COX2), which further weaken the BBB and allow tumor cells to penetrate the brain parenchyma. ${ }^{43}$ Avraham et al observed that TNBC cells disrupted the BBB, increased BBB permeability, and changed the structure of the $\mathrm{TJ}$ proteins $\mathrm{ZO}$ 1 and claudin-5. Meanwhile, angiopoietin-2 (Ang-2) expression was elevated in brain microvascular endothelial cells (BMECs). Targeted inhibition of Ang-2 prevented BMEC instability and the disruption of BBB integrity, thereby helping to inhibit TNBC cell colonization in the brain. ${ }^{44}$ TNBCBM was negatively correlated with the expression of glucose transporter 1 (GLUT1) and/or breast cancer resistance protein (BRCP) in intratumoral microvessels, suggesting that TNBCBM might be related to the disruption of the BBB. ${ }^{45}$

A comparison of the gene expression profiles of primary breast cancer samples that metastasized to the brain with those that metastasized to other organs, showed that the 
regulation of $\mathrm{T}$ cell activation was more prominent in BMrelated samples $(P<0.00002)$. Other studies have shown that $\mathrm{T}$ lymphocytes can increase the ability of breast cancer cells, especially ER-negative breast cancer, to cross the $\mathrm{BBB}$ and promote tumor invasion and metastasis in the brain tissue. These effects may have been mediated through the upregulation of guanylate-binding protein 1 (GBP1) at both the mRNA and protein levels. ${ }^{46}$ Another study showed that the increased GBP1 protein expression was associated with metastasis and poor prognosis in TNBC. ${ }^{47}$

Increasing evidence suggests that a close relationship exist between the gut microbiome and CNS diseases. Gut infection or dysbiosis of the gut microbiome promotes a series of changes in the $\mathrm{BBB}$ through interaction with the peripheral immune and neuroimmune systems. Factors secreted by gut microorganisms enter the circulation and interact with various immune cells (including $\mathrm{T}$ cells), thereby stimulating effector $\mathrm{T}$ cell differentiation, which can promote $\mathrm{T}$ cell brain infiltration. Meanwhile, circulating bacterial factors can up-regulate inflammatory cytokines levels, which can affect BBB integrity and promote neuroinflammation and CNS diseases. ${ }^{48}$

\section{The Blood-Tumor Barrier (BTB) in BM}

Similar to the BBB, the presence of the BTB also limits the access of potentially effective drugs to BM. The excessive production of proangiogenic factors in metastatic tumors, such as BM from breast cancer or other cancers, stimulates abnormal angiogenesis, resulting in a vasculature characterized by the presence of fenestrated vessels that increase paracellular permeability, referred to as the BTB (Figure 2). ${ }^{49}$ In contrast to the normal BBB, the BTB is leaky and tends to allow the extravasation of lager molecules. ${ }^{50}$ However, BTB permeability exhibits clear heterogeneity, both within lesions and among the BMs of different breast cancer subtypes. High expression of the pericyte protein desmin was shown to be correlated with the increased permeability of the BTB, indicative of the involvement of vascular remodeling. ${ }^{51}$

Understanding the cellular and molecular changes inherent to the transformation of the BBB to a BTB, and then from a poorly permeable BTB to a highly permeable one, may identify targetable pathways to improve the efficacy of drug therapy in the brain. When BM occurs,
A

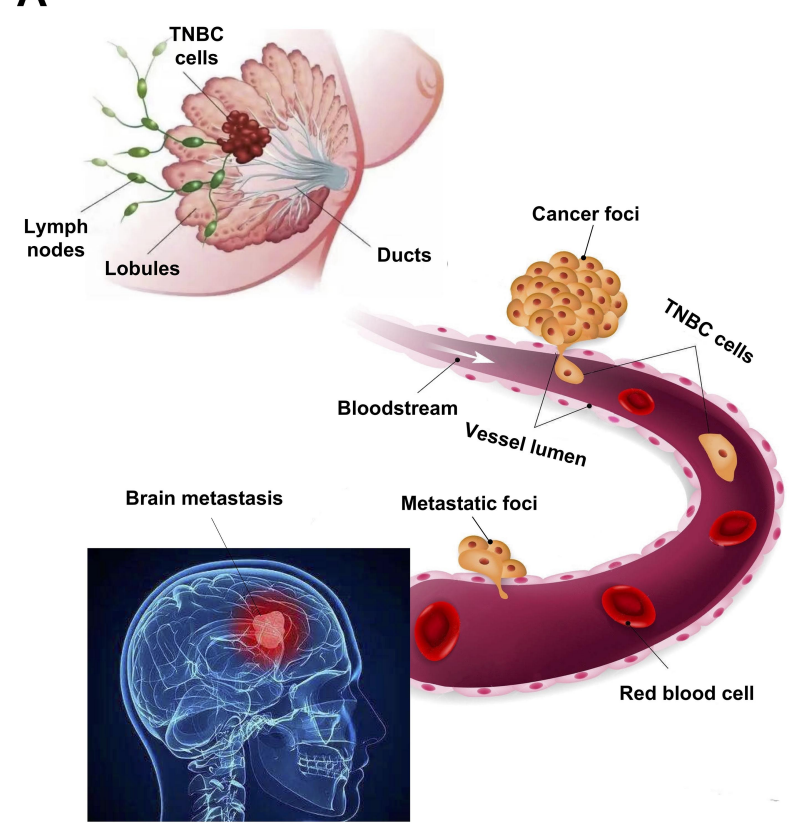

B

C

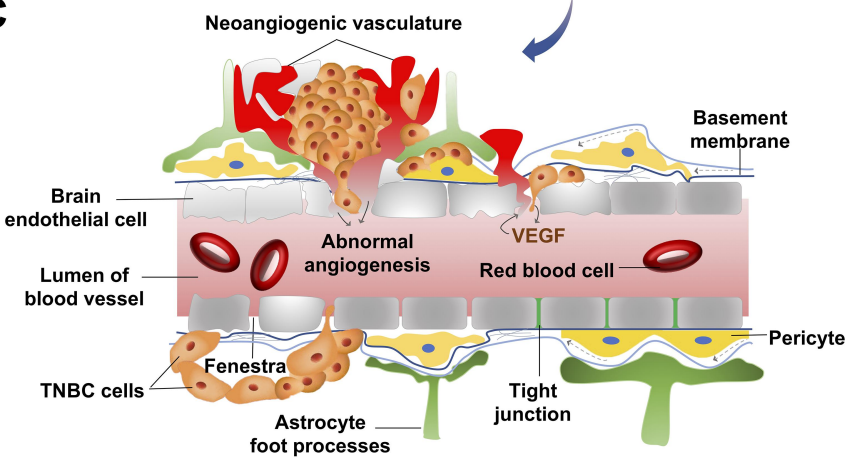

Figure 2 Triple-negative breast cancer brain metastasis (TNBCBM) and the composition of the blood-brain barrier (BBB) and blood-tumor barrier (BTB). (A) TNBC cells separate from the primary site and are transported to the brain via the blood; they eventually colonize the brain, forming BM. (B) The BBB is a complex structure formed via the physicochemical interactions of brain endothelial cells, pericytes, astrocytes, tight junctions, and efflux pumps, and is highly selective for endogenous and exogenous substances. (C) Cancer cells cross the BBB and stimulate abnormal (immature) angiogenesis, which is characterized by a fenestrated vasculature with increased permeability (the BTB). This change facilitates the entry of otherwise restricted substances into the brain parenchyma. 
the components of endothelial cells, pericytes, astrocytes, and microglia change. Lyle et al indicated that the transformation of a BBB to a BTB did not involve random destruction of the $\mathrm{BBB}$, but rather a consistent change in multiple BBB cell components. BTB permeability varies from tumor to tumor or even within each metastasis. When BMs grow beyond their blood supply, they become hypoxic, thus causing tumor cells to secrete VEGF and induce neovascularization. VEGF expression in TNBCBM, is $1.08 \times 10^{5}$-fold that of the uninvolved brain, and is significantly higher than that in HER2-positive cancer and inflammatory breast cancer. Notably, the increased expression of a desmin ${ }^{+}$subpopulation of pericytes, and the decreased expression of $\mathrm{CD} 13^{+}$pericytes and laminin $\alpha 2$ were associated with higher permeability in TNBCBM. $^{52,53}$

\section{Biological Characteristics of TNBCBM}

The mechanisms involved in $\mathrm{BM}$ progression once the TNBC cells have crossed the BBB remain poorly understood. Studies focusing on gene expression levels have shown that numerous genes play important roles in regulating tumor metastasis. High-resolution clonal mapping of multiorgan metastasis in TNBC revealed that tumors at different metastatic sites display specific gene patterns. Although brain, lung, liver, and multiorgan metastatic tumors have similar genetic characteristics, their gene expression programs can vary, possibly due to the diverse organ microenvironments. ${ }^{54}$ Siegel et al showed that gene mutations that originated in the primary tumors were maintained throughout metastatic spreading. These authors also showed that TP53 was the only driver gene that was mutated in all the subtypes of breast cancer metastasis analyzed, and that the alterations in other driver genes were mainly associated with somatic copy number alterations (CNAs). This study further expanded on the evidence of multiclonal seeding across multiple subtypes of breast cancer, especially for TNBC. ${ }^{55}$ Some studies have also implicated genes such as NAMPT, SREBP1, and MTHD as drivers of TNBC metastatic progression. ${ }^{56-58}$ Inactivating mutations in $A R I D 1 A$ are more common in TNBCBMs $(83 \%)$ than in HER2-positive $(51 \%)$ or HRpositive $(71 \%)$ tumors. $^{59}$ Interestingly, mutations in $A R I D 1 A$ often occur together with mutations in $P I K 3 C A$ or $P T E N$, and double mutations involving $A R I D I A$ and $P I K 3 C A$ or $P T E N$ result in ovarian tumor formation in mice, suggesting that $\mathrm{PI} 3 \mathrm{~K}$ and chromatin remodeling pathways play a synergistic carcinogenic role in TNBCs. ${ }^{60}$ However, further studies are needed on the role of ARID1A expression in TNBCBMs. Qian et al analyzed the gene expression profiles of 4801 breast cancer patients from 27 publicly available breast cancer datasets, and found that a Chromosome 3q 19-gene signature was closely associated with breast cancer-related aggressiveness and reduced distant metastasis-free survival, especially in TNBC. They further identified that the $3 q$ signature was an independent predictor of metastasis to the brain in TNBC patients (hazard ratio [HR]: $1.61,95 \%$ confidence interval $[\mathrm{CI}]: 1.21 \sim 2.13 ; P=0.001)$. $P I K 3 C A$ is one of the most extensively studied oncogenes among the $3 q$ 19-gene signature. The authors of this study also reported that $P I K 3 C A$ expression was significantly correlated with $\mathrm{BM}$, while PIK3CA mRNA expression was correlated to its CNAs, but not mutation status, in breast cancer. $^{61}$

Epigenetic changes are increasingly recognized as key events in breast cancer progression. Yomtoubian et al identified enhancer of zeste homolog 2 (EZH2) as a major driver of TNBC progression through a metaanalysis of epigenetic genes. TNBC cells with high EZH2 expression exhibited stronger metastatic potential, and blockading the catalytic activity of $\mathrm{EZH} 2$ could reduce TNBC dissemination and metastasis. ${ }^{62}$ Among identified TNBC-specific transcription factors, engrailed 1 (EN1) was found to be high expressed in TNBC, and was associated with the regulation of neurogenesis-related genes (such as $N L G N 4 X$ and other neuroligin-encoding genes) and an increased risk of BM in TNBC patients. ${ }^{63}$ In conclusion, studies relating to molecular and genetic variants associated with TNBCBM provide hope for the prevention of $\mathrm{BM}$ in high-risk TNBC patients.

\section{The CNS Microenvironment}

The process of distant metastasis is extremely inefficient, with less than $0.01 \%$ of primary tumor cells completing the invasion-metastasis cascade and forming metastases in secondary organs. ${ }^{64}$ Most cancers are known to show an organ-specific pattern of metastasis, which suggests that metastatic growth is not random, but is instead influenced by the microenvironment of the secondary organs. A better understanding of the mechanisms of metastatic diseases in recent years has tended to support the "seed and soil" hypothesis proposed by Steven Paget. 65 The spread of tumor cells is determined by the interaction and 
cooperation between the cancer cells ("seeds") and the secondary organ ("soil"), and only falling on suitable "soil" can contribute to the colonization of "seeds". The unique biological characteristics and specific cells and molecular components of the secondary organ microenvironment promote the formation of metastasis, and blocking these signals may help to inhibit this process. ${ }^{66}$

\section{The Tumor Microenvironment: Creating a Pre-Metastatic Niche in the Brain}

TNBC exhibits numerous CSC-like traits and is more likely to lead to BM. The short time to BM occurrence in TNBC and the short survival time after BM diagnosis may be indicative of an innate ability of TNBC cells to adapt to the brain microenvironment. ${ }^{67}$ The vascular basement membrane presents the "soil" in BM. Although more than $95 \%$ of early brain micrometastases were shown to coexist with blood vessels, there is little evidence for isolated neurogenic growth. ${ }^{68}$ When TNBC cells invade the brain parenchyma, an adequate blood supply is needed to provide the nutrients necessary for tumor growth and proliferation. Tumor angiogenesis depends on the balance between pro- and anti-angiogenic factors at the local tissue level and is regulated by the local microenvironment. ${ }^{69}$

When TNBC cells cross the BBB, TNBC cells begin to interact with the extracellular matrix (ECM), brain parenchymal resident cells (astrocytes and other stromal cells), and paracrine signaling molecules (cytokines and growth factors) in the brain microenvironment. Primary TNBC cells locally invade and systemically disseminate through EMT-related processes, while the reverse (mesenchymal-to-epithelial transition; MET) is involved in metastatic colonization in the brain. $^{70}$ Zhang et al demonstrated that, in the brain microenvironment, epigenetic regulation mediated by astrocyte-derived miRNA could reduce the expression of PTEN, which is normally expressed in human and mouse tumor cells. The loss of the expression of this tumor suppressor gene promoted the growth of brain metastatic tumor cells by enhancing proliferation and reducing apoptosis. A subsequent blockade of astrocyte secretion restored PTEN levels and suppressed $\mathrm{BM}$ in vivo, reflecting the dependence of BM on the brain microenvironment. This study also found that the loss of PTEN was associated with the TNBC subtype and predicted a shorter survival time. ${ }^{71}$ Hohensee et al further demonstrated that the loss of PTEN expression was significantly associated with TNBCBM $(P=0.001)$ and shorter survival time after surgical BM resection $(P=0.048)$. In an in vitro model, the upregulation of PTEN in TNBC led to reduced cell migration and invasion to the brain, which was primarily mediated by autocrine and paracrine activation of the GM-CSF/CSF2RA and AKT/PTEN pathways. ${ }^{72}$

\section{Immunosurveillance Escape: Maintaining an Immunosuppressive Environment by Regulating Neuroinflammation}

Tumor-associated macrophages (TAMs) are important components of the metastatic microenvironment. Metastasis-associated macrophages (MAMs) show TNBCBM site-dependent differences in their molecular profiles. Lymphotoxin $\beta$ was the most significantly upregulated cytokine in TNBC cells metastasized to the brain parenchyma compared with that in the dura mater and was suggested to be directly involved in the M2 polarization of brain parenchymal MAMs. This suggested that there may be a link between the site specificity of metastatic TNBC cells and the MAM activation state. ${ }^{73} \mathrm{BM}$ is also modified by other CNS microenvironment-derived factors. The expression of gamma-aminobutyric acid (GABA) transporters was increased in BMs derived from TNBC and HER2-positive breast cancer compared with that in matched primary tumor tissues and the BMs, particularly TNBCBMs, were able to proliferate by metabolizing GABA as a biosynthetic energy source, which was more prominent in TNBCBM. ${ }^{74}$

A better understanding of the immunogenicity of the BM environment may help explain how immunotherapy can help in the treatment of BM, although this is still in its infancy. Tumor-infiltrating lymphocytes (TILs) have a prognostic role in TNBC, with higher levels of TILs being associated with a lower rate of distant metastasis. The immune environment in BM is poorly characterized. TIL levels are lower in BM than in primary breast cancer, and the number of $\mathrm{CD}^{+}$and $\mathrm{CD}^{+} \mathrm{T}$ cells was significantly decreased in the brain. ${ }^{75} \mathrm{~A}$ recent study also showed that BMs have reduced immune cell recruitment (including $\mathrm{CD}^{+} \mathrm{T}$ cells, regulatory $\mathrm{T}$ cells, and dendritic cells) but increased relative levels of M2-like macrophages when compared with their matched primary breast cancers, particularly the TNBC subtype. ${ }^{76}$ The lower infiltration of immune cells in BM may be due to immune escape. Sambade et al studied four histological biomarkers - gliosis, immune infiltrate, hemorrhage, and necrosis-and 
their prognostic significance in BMs. In 203 BM samples, necrosis was significantly higher in TNBCBMs (comprising $38 \%$ of the 203 samples) than in BMs derived from other breast cancer subtypes $(P<0.01)$. Gliosis was associated with improved OS in TNBC $(P=0.02)$, while immune infiltrate $(P=0.001)$ and hemorrhage $(P=0.07)$ were associated with the HER-positive subtype. ${ }^{77}$ Immune cells are involved in, and constantly change during, the progression of the primary tumor and its metastatic cascade within individual patients.

\section{Metabolic Adaptations: Meeting the High Energy Demands for Survival and Proliferation}

Metabolic adaptations are also important for the growth and survival of metastatic TNBC cells within the CNS environment. Enzymes involved in glucose-associated aerobic and anaerobic processes are upregulated to meet the high energy demands of metastatic cells in the brain, enabling them to survive and proliferate within the lowglucose microenvironment. ${ }^{7}$ Metabolic reprogramming is increased in TNBCBM cells, and glucose metabolism is more intensive. GLUT3 is crucial for the survival of TNBC cells in the brain, while its overexpression promotes prometastatic signaling in TNBCBM cells, and also significantly enhances the malignant behavior of TNBC cells. ${ }^{78}$ TNBC mostly displays high levels of glycolysis. The level of glycolysis is higher in BM cells than in other metastatic sites or the associated primary cancer. The upregulated expression of lactate dehydrogenase A (LDH-A), which catalyzes the final step of glycolysis, is closely associated with TNBCBM. The upregulation of LDH-A enhances the adaptation of TNBC cells to the brain environment and is also a reflection of a high metabolic rate, thus contributing to tumor proliferation. ${ }^{79}$ Meanwhile, metastatic cells can also utilize the abundant amino acids (glutamine, branched-chain amino acids) in the CNS to carry out amino acid-dependent gluconeogenesis and store glycogen. ${ }^{7}$ Valine is an essential branchedchain amino acid catabolized in the brain. Kalita-de Croft et al analyzed the proteomic characteristics of TNBCBM and found that 3-hydroxyisobutyryl-CoA hydrolase (HIBCH) was essential for gluconeogenic valine catabolism in the brain; HIBCH was strongly induced in BM, and was mostly expressed at metastatic margins and hemorrhagic areas. Their findings further supported that valine catabolism may be an effective adaptation of TNBC cells to the brain microenvironment, and that its intermediates or products can be transferred from tumor-associated glial cells. ${ }^{80}$ The upregulation of lipolysis promotes metastasis, especially in TNBCBM. Oncogenic lipid signaling supports TNBC cell migration to the brain by promoting cell survival, migration, and invasion. The inhibition of key enzymes in lipolysis, such as monoacylglycerol lipase (MAGL) and alkyl glycerophosphate synthase (AGPS), reduces the metastatic potential of tumor cells. The metabolic phenotypes differ among different breast cancer subtypes, with the TNBC exhibiting the metabolically active Warburg/mixed phenotypes. ${ }^{81,82}$ A recent study reported that estradiol may upregulate neurotrophin receptor tropomyosin kinase receptor B (TRKB) signaling in premenopausal women with $\mathrm{TNBC}$, thereby promoting $\mathrm{BM}$ development. ${ }^{83}$ Because of the increased metabolism associated with TNBCBM, patients with this condition may benefit the most from metabolic interventions. Understanding the BM microenvironment may contribute to identifying prognostic factors and new therapeutic strategies.

The development of TNBCBM involves a complicated multifactorial metastatic cascade. The main steps of metastasis include TNBC cell detachment from the primary site; invasion of the surrounding stromal and basement membrane; survival in the circulatory system (intravasation and extravasation); breaking down the BBB; the formation of a highly permeable BTB; CNS invasion; and BM colonization. ${ }^{42}$ The metastatic cascade is summarized in Figure 3.

\section{Clinical Trials Involving TNBCBM}

The widespread concern that most drugs are not likely to penetrate the BBB results in the exclusion of patients with breast cancer and other primary tumors from clinical trials. ${ }^{84}$ This reduces the exposure of BM patients to potentially beneficial novel agents and limits important correlative studies of brain-specific tumor responses. However, new treatment options are urgently needed for TNBCBM patients. In recent years, with a deeper understanding of the molecular changes occurring in TNBC, several promising clinical strategies have emerged, including, among others, treatment with poly adenosine diphosphate-ribose polymerase (PARP) inhibitors, VEGF inhibitors, and immune checkpoint inhibitors, which are currently under evaluation. Here, we review the completed TNBCBM-related clinical trials (Table 1) and summarize those that are ongoing (Table 2). 


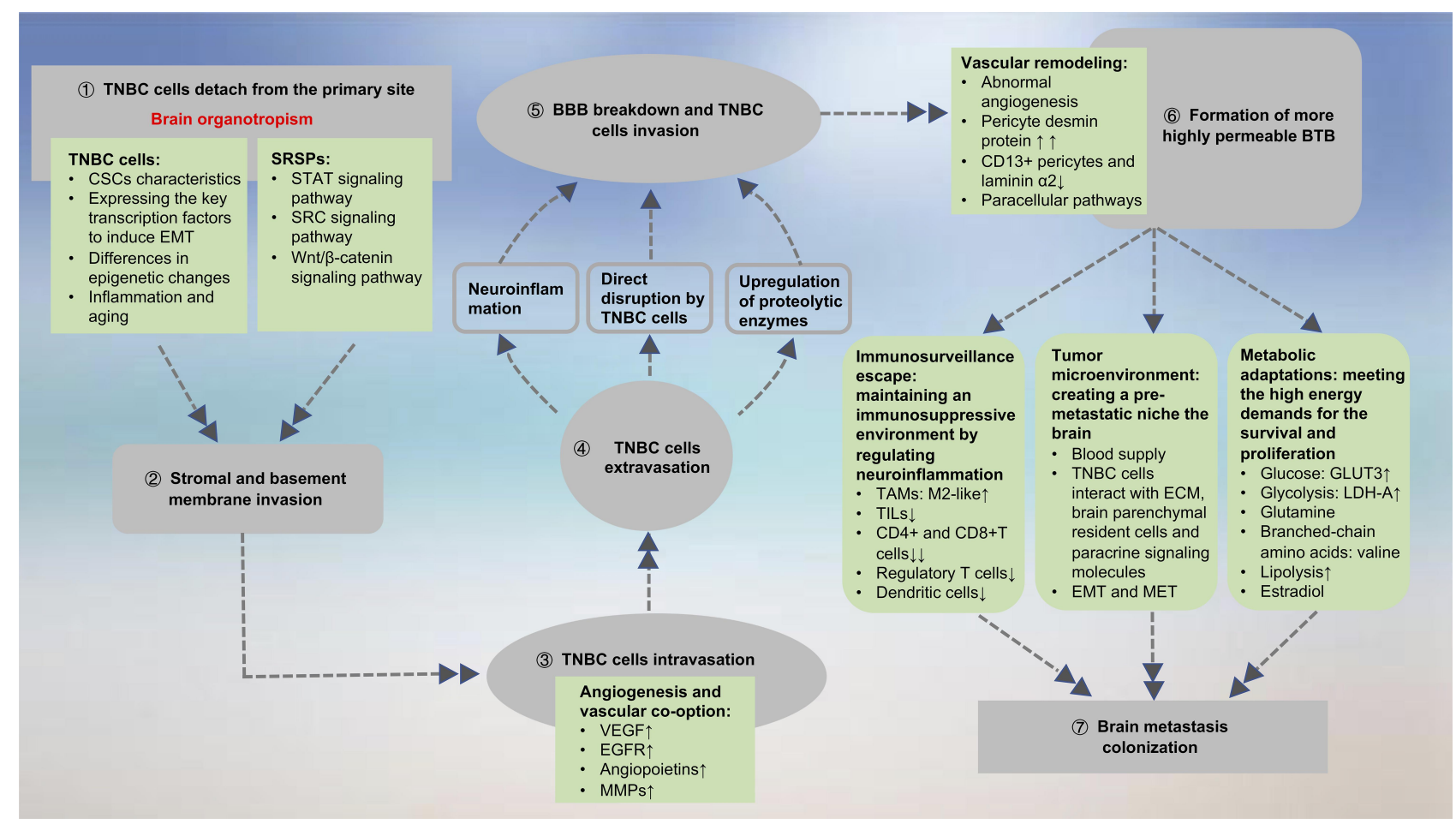

Figure 3 Summary of the metastatic cascade and pathways promoting brain metastasis. The upward arrows ( $\uparrow$ ) indicates increased expression, and ( $\uparrow$ ) indicates overexpression. The down arrow $(\downarrow)$ represents a reduction, and $(\downarrow \downarrow)$ represents a significant reduction.

Abbreviations: TNBC, triple-negative breast cancer; CSC, cancer stem cell; EMT, epithelial-to-mesenchymal transition; SRSP, self-renewal signaling pathway; STAT, signal transducer and activator of transcription; SRC, protooncogene tyrosine-protein kinase Src; VEGF, vascular endothelial growth factor; EGFR, epidermal growth factor receptor; MMP, matrix metalloproteinase; BBB, blood-brain barrier; BTB, blood-tumor barrier; TAM, tumor-associated macrophage; TIL, tumor-infiltrating lymphocyte; MET, mesenchymal-to-epithelial transition; LDH-A, lactate dehydrogenase A.

PARP is a key enzyme in DNA single-strand break repair. PARP inhibitors prevent self-repair in BRCA 1/ 2-mutated cancer cells and induce PARP capture at the site of DNA damage; this, in combination with cytotoxic DNA-damaging chemotherapeutic drugs (such as platinum analogs), accelerates cancer cell death. ${ }^{85} \mathrm{~A}$ preclinical study demonstrated that carboplatin combined with veliparib (a PARP inhibitor) could reduce BBB permeability, inhibit the growth of TNBC-derived intracranial metastatic tumors, and improve prognosis. ${ }^{86} \mathrm{~A}$ phrase II clinical trial combining cisplatin with veliparib for the treatment of TNBCBM with or without $B R C A$ mutations is currently being conducted (NCT02595905) and is expected to be completed by October 31, 2021. Talazoparib belongs to a new generation of PARP inhibitors with strong catalytic inhibitory activity and has a 100 -fold greater PARPtrapping potential than other PARP inhibitors currently under investigation. A Phase III clinical trial of talazoparib (EMBRACA) was conducted on 431 patients with advanced breast cancer and a germline $B R C A 1 / 2$ mutation (including 190 TNBC patients). Among the patients with $\mathrm{BM}$, median progression-free survival (PFS) was significantly longer in the talazoparib group than in the chemotherapy group (HR $=0.32,95 \%$ CI: $0.15 \sim 0.68)$, suggesting that talazoparib can penetrate the $\mathrm{BBB} .{ }^{87}$ Another Phase II clinical trial (ABRAZO) demonstrated that talazoparib exerted antitumor activity in patients with advanced TNBCBM who had a previous response to platinum chemotherapy, as well as in those who received at least three previous cytotoxic regimens without prior platinum exposure. The objective response rate (ORR) of TNBC was $26 \%$, and a longer platinum-free interval was associated with a higher response rate. ${ }^{88}$

Iniparib mainly acts by changing reactive oxygen species metabolism in tumor cells, and may also function as a PARP inhibitor. Its unique physical properties (ie, low molecular weight and lipophilic nature) may favor BBB penetration, making it a promising candidate for targeting BM. In a Translational Breast Cancer Research Consortium (TBCRC) 018 phase II clinical trial, a total of 34 TNBC patients with new or progressive BM were treated with iniparib combined with irinotecan and then evaluated for a curative effect. The median progression time was 2.14 months and the median OS was 7.8 months. 
Table I Selected Completed Clinical Trials for Triple-Negative Breast Cancer Brain Metastasis (TNBCBM)

\begin{tabular}{|c|c|c|c|c|c|c|c|}
\hline Drug & $\begin{array}{l}\text { ClinicalTrials. } \\
\text { gov Identifier }\end{array}$ & Phase & $\begin{array}{l}\text { Number } \\
\text { of } \\
\text { Patients }\end{array}$ & $\begin{array}{l}\text { Experimental Arm } \\
\text { (Regimen and } \\
\text { Dose) }\end{array}$ & $\begin{array}{l}\text { Control Arm } \\
\text { (Regimen and } \\
\text { Dose) }\end{array}$ & Status & Results \\
\hline Talazoparib & NCTOI $945775^{89}$ & III & $\begin{array}{l}431 \\
\text { advanced } \\
\text { breast } \\
\text { cancer } \\
\text { patients } \\
\text { (190 } \\
\text { TNBC) }\end{array}$ & $\begin{array}{l}\text { Talazoparib I mg } \\
\text { once daily }\end{array}$ & $\begin{array}{l}\text { Standard single-agent } \\
\text { therapy (capecitabine, } \\
\text { eribulin, gemcitabine, } \\
\text { or vinorelbine every } \\
2 \text { I days) }\end{array}$ & Recruiting & $\begin{array}{l}\text { The talazoparib } \\
\text { group showed } \\
\text { a } 3 \text {-month extension } \\
\text { of PFS and a } 35.4 \% \\
\text { increase in ORR } \\
(62.6 \% \text { vs } 27.2 \%) \\
\text { compared with the } \\
\text { standard-therapy } \\
\text { group. For BM } \\
\text { patients, talazoparib } \\
\text { also prolonged PFS. }\end{array}$ \\
\hline Talazoparib & NCT02034916 $6^{90}$ & II & $\begin{array}{l}84 \text { patients } \\
\text { with } \\
\text { advanced } \\
\text { breast } \\
\text { cancer } \\
\text { ( } 35 \\
\text { TNBC) }\end{array}$ & $\begin{array}{l}49 \text { patients (59\% } \\
\text { TNBC) with } \\
\text { a complete or partial } \\
\text { response to } \\
\text { a previous platinum- } \\
\text { containing regimen, } \\
\text { with no disease } \\
\text { progression within } 8 \\
\text { weeks of the last dose } \\
\text { of platinum therapy. } \\
\text { Talazoparib I mg } \\
\text { once daily }\end{array}$ & $\begin{array}{l}35 \text { patients ( } 17 \% \\
\text { TNBC) who had } \\
\text { received three or } \\
\text { more previous } \\
\text { cytotoxic } \\
\text { chemotherapy } \\
\text { regimens and no } \\
\text { previous platinum } \\
\text { therapy. Talazoparib } \\
\text { I mg once daily }\end{array}$ & Recruiting & $\begin{array}{l}\text { BM accounted for } \\
\text { I I\% of metastatic } \\
\text { disease. Talazoparib } \\
\text { had clinical activity in } \\
\text { both groups of } \\
\text { patients (ORR: } 21 \% \\
\text { vs } 37 \% \text {; median } \\
\text { duration of response: } \\
5.8 \text { vs } 3.8 \text { months). } \\
\text { ORR was } 26 \% \text { in } \\
\text { TNBC. }\end{array}$ \\
\hline Iniparib & NCTOII $73497^{91}$ & ॥ & $\begin{array}{l}37 \\
\text { TNBCBM } \\
\text { patients }\end{array}$ & $\begin{array}{l}\text { Irinotecan } 125 \mathrm{mg} / \mathrm{m}^{2} \\
\mathrm{dl}, 8+\text { iniparib } 5.6 \mathrm{mg} / \\
\mathrm{kg} \mathrm{dl}, 4,8, \mathrm{II} \text { every } 2 \mathrm{I} \\
\text { days (when a new } \\
\text { brain metastases } \\
\text { occurred, the dose of } \\
\text { iniparib was raised to } \\
8 \mathrm{mg} / \mathrm{kg} \text { ) }\end{array}$ & None & Recruiting & $\begin{array}{l}\text { Progression time was } \\
\text { the primary endpoint; } \\
\text { secondary endpoints } \\
\text { were RR, CBR, OS, } \\
\text { etc. } \\
\text { A modest benefit of } \\
\text { irinotecan plus } \\
\text { iniparib in progressive } \\
\text { TNBCBM. }\end{array}$ \\
\hline Bevacizumab & NCTOI $281696^{92}$ & II & $\begin{array}{l}35 \text { patients } \\
\text { with BM } \\
\text { from } \\
\text { breast } \\
\text { cancer (6 } \\
\text { TNBC) }\end{array}$ & $\begin{array}{l}\text { Bevacizumab } 15 \mathrm{mg} / \mathrm{kg} \\
\mathrm{dl}+\text { etoposide } 70 \mathrm{mg} / \\
\mathrm{m}^{2} / \mathrm{d} \mathrm{d} 2-4+\text { cisplatin } \\
70 \mathrm{mg} / \mathrm{m}^{2} \mathrm{~d} 2 \\
\text { every } 2 \mathrm{I} \text { days }\end{array}$ & None & Recruiting & $\begin{array}{l}27 \text { patients }(77.1 \%) \\
\text { with a } \geq 50 \% \\
\text { volumetric reduction } \\
\text { in CNS lesion, } \\
\text { including I } 3 \text { patients } \\
\text { (37.I\%) with a } \geq 80 \% \\
\text { reduction. All TNBC } \\
\text { patients responded } \\
\text { to this treatment. }\end{array}$ \\
\hline
\end{tabular}

(Continued) 
Table I (Continued).

\begin{tabular}{|c|c|c|c|c|c|c|c|}
\hline Drug & $\begin{array}{l}\text { ClinicalTrials. } \\
\text { gov Identifier }\end{array}$ & Phase & $\begin{array}{l}\text { Number } \\
\text { of } \\
\text { Patients }\end{array}$ & $\begin{array}{l}\text { Experimental Arm } \\
\text { (Regimen and } \\
\text { Dose) }\end{array}$ & $\begin{array}{l}\text { Control Arm } \\
\text { (Regimen and } \\
\text { Dose) }\end{array}$ & Status & Results \\
\hline Atezolizumab & NCT0242589195 & III & $\begin{array}{l}902 \\
\text { metastatic } \\
\text { TNBC } \\
\text { patients, } \\
\text { including } \\
61 \mathrm{BM} \\
\text { patients }\end{array}$ & $\begin{array}{l}\text { Atezolizumab } 840 \mathrm{mg} \\
\mathrm{dI}, 15+\text { nab- } \\
\text { paclitaxel } 100 \mathrm{mg} / \mathrm{m}^{2} \\
\mathrm{dI}, 8,15 \\
\text { every } 28 \text { days }\end{array}$ & $\begin{array}{l}\text { Placebo } 840 \mathrm{mg} \mathrm{dI,I5} \\
+ \text { nab-paclitaxel } \\
100 \mathrm{mg} / \mathrm{m}^{2} \mathrm{dI}, 8,15 \\
\text { every } 28 \text { days }\end{array}$ & Recruiting & $\begin{array}{l}\text { Atezolizumab plus } \\
\text { nab-paclitaxel } \\
\text { prolonged PFS and } \\
\text { OS (PFS: } 7.2 \text { months } \\
\text { vs } 5.5 \text { months, } \\
P=0.002 \text {; OS: } 21.3 \\
\text { months vs } 17.6 \\
\text { months, } P=0.08 \text { ). }\end{array}$ \\
\hline
\end{tabular}

Abbreviations: PFS, progression-free survival; OS, overall survival; CNS, central nervous system; CBR, clinical benefit rate; RR, response rate; ORR, objective response rate.

The intracranial response rate (RR) was $12 \%$, the intracranial clinical benefit rate (CBR) was $27 \%$, and the treatment was well-tolerated. ${ }^{89}$

VEGF plays an important role in BM angiogenesis. Bevacizumab is a VEGF inhibitor that has shown potential in the treatment of breast cancer BM. A window period between the administration of bevacizumab and that of cytotoxic drugs may optimize the CNS response to advanced breast cancer BM, including TNBCBM, after WBRT. $^{90}$ TNBC is the most immunogenic breast cancer subtype, rendering the inhibition of programmed cell death protein 1 receptor (PD-1) and programmed cell death protein 1 receptor ligand (PD-L1) attractive therapeutic targets. Atezolizumab (PD-L1 antibody) induces TNBC cell death/apoptosis and reduces their proliferative/metastatic potential and viability. ${ }^{91}$ One study suggested that immune checkpoint inhibitors may have therapeutic effects in BM. $^{92}$ The IMpassion 130 phase III study showed that atezolizumab plus nab-paclitaxel prolonged PFS and OS among patients with metastatic TNBC, including those with BM. ${ }^{93}$

\section{Potential Therapeutic Targets for TNBCBM Treatment}

TNBCBM patients are still followed by the current medical community, and continuous exploration of valuable potential therapeutic targets is the priority of the future research. The ultimate goal is to reduce the incidence of $\mathrm{BM}$ and prolong the survival period of these patients. We review the emerging therapeutic targets with the aim of laying the foundation for the treatment of TNBCBM.

\section{MicroRNAs}

Growing evidence has indicated that miRNAs play a role in the different steps of BM development and that they can regulate the expression of multiple gene. Accordingly, miRNAs are regarded as attractive therapeutic targets for the treatment of cancer metastasis. ${ }^{94}$ Debeb et al showed that the overexpression of miR-141 in TNBC cells enhanced $\mathrm{BM}$ colonization, while its knockdown inhibited the ability of inflammatory TNBC to metastasize to the brain. Additionally, high miR-141 serum levels have been associated with shorter BM-free survival $(P=0.04)$ and were independent predictors of PFS and OS. This suggests that miR-141 may be a regulator of TNBCBM and has the potential for use as a biomarker and potential target for the prevention and treatment of BM. ${ }^{95}$ Wang et al demonstrated that TNBC cells can secrete miR-122, which promotes metastasis by increasing nutrient availability in the premetastatic niche, and downregulates glucose uptake in astrocytes. The inhibition of miR-122 in vivo restored glucose uptake in distant organs (including the brain), thereby reducing the incidence of BM. ${ }^{96}$ MiR-509 significantly inhibited the ability of TNBC cells to metastasize to the brain through regulating the expression of two genes$T N F$ and $R H O C$ - that affect brain invasion. ${ }^{97}$ MiR-7 weakens the invasive and self-renewal ability of breast cancer stem cells by downregulating the expression of the KLF4 gene, thereby specifically inhibiting BM. ${ }^{98}$ Another study reported that miR-20b levels were increased in BM cells, including those derived from TNBC. MiR$20 \mathrm{~b}$ also significantly enhanced the colony-forming ability of breast cancer cells as well as their aggressiveness; however, where miR-20b has potential as a therapeutic 
Table 2 Selected Ongoing Clinical Trials for Triple-Negative Breast Cancer Brain Metastasis (TNBCBM)

\begin{tabular}{|c|c|c|c|c|c|c|c|}
\hline $\begin{array}{l}\text { ClinicalTrials. } \\
\text { gov Identifier }\end{array}$ & Title & $\begin{array}{l}\text { Phase } \\
\text { and } \\
\text { Status }\end{array}$ & $\begin{array}{l}\text { No of } \\
\text { Patients }\end{array}$ & Lead & Study Intervention & $\begin{array}{l}\text { Primary } \\
\text { Outcome }\end{array}$ & $\begin{array}{l}\text { Secondary } \\
\text { Outcome }\end{array}$ \\
\hline $\begin{array}{l}\text { NСТ04303988, } \\
\text { 2020, Jian Zhang }\end{array}$ & $\begin{array}{l}\text { A prospective, single-arm, } \\
\text { single-center, multi-cohort } \\
\text { phase II clinical study of HER2- } \\
\text { positive and triple-negative } \\
\text { breast cancer brain Metastases }\end{array}$ & $\begin{array}{l}\text { Il, active, } \\
\text { no } \\
\text { recruiting }\end{array}$ & 59 & $\begin{array}{l}\text { Fudan } \\
\text { University }\end{array}$ & $\begin{array}{l}\text { TNBC patients will } \\
\text { receive SHRI3I6 in } \\
\text { combination with } \\
\text { bevacizumab plus } \\
\text { cisplatin or } \\
\text { carboplatin }\end{array}$ & $\begin{array}{l}\text { ORR in } \\
\text { the CNS }\end{array}$ & $\begin{array}{l}\text { CBR in the } \\
\text { CNS; PFS; } \\
\text { OS; first } \\
\text { progression } \\
\text { site; safety }\end{array}$ \\
\hline $\begin{array}{l}\text { NCT034830I2, } \\
2018, \text { Nancy U } \\
\text { Lin }\end{array}$ & $\begin{array}{l}\text { A phase II study of } \\
\text { atezolizumab in combination } \\
\text { with stereotactic radiation for } \\
\text { patients with triple-negative } \\
\text { breast cancer and brain } \\
\text { metastasis }\end{array}$ & $\begin{array}{l}\text { II, } \\
\text { recruiting }\end{array}$ & 45 & $\begin{array}{l}\text { Dana- } \\
\text { Farber } \\
\text { Cancer } \\
\text { Institute }\end{array}$ & $\begin{array}{l}\text { Atezolizumab + } \\
\text { stereotactic } \\
\text { radiosurgery }\end{array}$ & PFS & $\begin{array}{l}\text { Extracranial } \\
\text { ORR; PFS; } \\
\text { CBR; OS; } \\
\text { neurological } \\
\text { evaluation }\end{array}$ \\
\hline $\begin{array}{l}\text { NCT02595905, } \\
\text { 2016, Eve T } \\
\text { Rodler }\end{array}$ & $\begin{array}{l}\text { Phase II randomized placebo- } \\
\text { controlled trial of cisplatin with } \\
\text { or without ABT-888 (Veliparib) } \\
\text { in metastatic triple-negative } \\
\text { breast cancer and/or BRCA } \\
\text { mutation-associated breast } \\
\text { cancer, with or without brain } \\
\text { metastases }\end{array}$ & $\begin{array}{l}\text { Il, active, } \\
\text { no } \\
\text { recruiting }\end{array}$ & 333 & $\begin{array}{l}\text { Anchorage } \\
\text { Associates } \\
\text { in } \\
\text { Radiation } \\
\text { Medicine }\end{array}$ & $\begin{array}{l}\text { Cisplatin } \mathrm{dl}+ \\
\text { veliparib } \mathrm{dI}-14 \text {, every } \\
2 \mathrm{I} \text { days }\end{array}$ & PFS & $\begin{array}{l}\text { OS; RR; } \\
\text { CBR }\end{array}$ \\
\hline $\begin{array}{l}\text { NCT02448576, } \\
\text { 20I7, Shusen } \\
\text { Wang }\end{array}$ & $\begin{array}{l}\text { A phase III randomized } \\
\text { controlled trial of prophylactic } \\
\text { cranial irradiation in patients } \\
\text { with advanced triple negative } \\
\text { breast cancer who had } \\
\text { a response to first line } \\
\text { chemotherapy }\end{array}$ & $\begin{array}{l}\text { III, active, } \\
\text { no } \\
\text { recruiting }\end{array}$ & 326 & $\begin{array}{l}\text { Sun Yat-sen } \\
\text { University } \\
\text { Cancer } \\
\text { Center }\end{array}$ & $\begin{array}{l}\text { Prophylactic cranial } \\
\text { irradiation in } \\
\text { advanced TNBC } \\
\text { patients who had } \\
\text { a response to first } \\
\text { line chemotherapy }\end{array}$ & $\begin{array}{l}\text { BM-free } \\
\text { survival }\end{array}$ & $\begin{array}{l}\text { Cumulative } \\
\text { risk of BM } \\
\text { within } \\
\text { one year; } \\
\text { PFS; OS; } \\
\text { CNS score }\end{array}$ \\
\hline $\begin{array}{l}\text { NCT03 I68880, } \\
\text { 20I7, Rajendra } \\
\text { A Badwe }\end{array}$ & $\begin{array}{l}\text { A randomized controlled trial } \\
\text { of neoadjuvant weekly } \\
\text { paclitaxel versus weekly } \\
\text { paclitaxel plus weekly } \\
\text { carboplatin in women with } \\
\text { large operable or locally } \\
\text { advanced, triple negative } \\
\text { breast cancer }\end{array}$ & $\begin{array}{l}\text { III, active, } \\
\text { no } \\
\text { recruiting }\end{array}$ & 720 & $\begin{array}{l}\text { Tata } \\
\text { Memorial } \\
\text { Centre }\end{array}$ & $\begin{array}{l}\text { Arm A: paclitaxel; } \\
\text { Arm B: paclitaxel + } \\
\text { carboplatin }\end{array}$ & $\begin{array}{l}\text { DFS and } \\
\text { OS }\end{array}$ & RR \\
\hline
\end{tabular}

Abbreviations: PFS, progression-free survival; OS, overall survival; CNS, central nervous system; CBR, clinical benefit rate; RR, response rate; ORR, objective response rate.

target remains unknown. ${ }^{99}$ Using next-generation sequencing (NGS), Sereno et al revealed that circulating miRNAs were dysregulated during TNBCBM progression. The authors found that the downregulation of miR-802-5p and miR-195-5p was a precocious event in TNBCBM, and that the transcription factor myocyte enhancer factor 2C (MEF2C) was a target of the two miRNAs, while MEF2C expression in TNBC cells was increased with BM development. ${ }^{100}$

\section{Long Noncoding RNAs}

Xing et al examined the lncRNA expression profiles in primary breast cancer and $\mathrm{BM}$ and found that $\mathrm{X}$-inactive specific transcript (XIST) was the top differentially expressed lncRNA between the two groups. XIST expression was significantly downregulated in BM compared with other metastatic tumors, with the most significant reduction being recorded in the TNBC subtype. In the study, the authors also established a TNBCBM mouse 
model, and found that XIST downregulation led to the activation of three different pathways, namely, EMT, $\mathrm{MSN} / \mathrm{c}-\mathrm{Met}$, and release of exosomal miR-503. Jointly, these pathways promoted the expression of metastatic traits in CSCs and triggered the upregulation of immunosuppressive factors in the CNS microenvironment through 1 exosome-mediated communication. In summary, lncRNA XIST exerts a metastasis-suppressive function preferentially in the brain, and its downstream pathway may be an effective target for the treatment of BM. ${ }^{101}$ Wang et al identified a lncRNA associated with breast cancer BM (lnc-BM), and found that the increased expression of lnc-BM in breast cancer cells (including TNBC cells) could drive BM progression, while lnc-BM depletion mediated through nanoparticle-encapsulated siRNAs elicited the opposite effect. Further investigation showed that interaction between lnc-BM and JAK2 enhanced the communication between breast cancer cells and the CNS microenvironment to promote BM. Targeting lnc-BM represents a potential strategy for treating BM. ${ }^{102}$

\section{Circular RNA}

Circular RNA (circRNA) expression was compared between TNBCBM cells and parental nonspecific metastatic cells. The results showed that hsa_circ_0001944, hsa_circ_0001481, hsa_circ_0000646, hsa_circ_0001006 and hsa_circ_0000732 were upregulated, whereas hsa_circ_0001910, hsa_circ_0008285, and hsa_circ_0000002 were downregulated. Further analysis indicated that hsa circ_0001944 might be involved in BM development by stimulating miR-509 and interfering with its binding to downstream targets. ${ }^{103}$

\section{Progesterone}

Membrane progesterone receptor alpha $(\mathrm{mPR} \alpha)$ is not associated with classical PR and is expressed in tissue lacking PR expression. Zhou et al demonstrated that $\mathrm{mPR} \alpha$ was highly expressed in TNBC tissues and that its expression level was negatively associated with TNM stage. The authors also showed that progesterone inhibited TNBC cell growth and metastasis to the brain via $\mathrm{mPR} \alpha$, and provided evidence of a new mechanism, mediated by the progesterone/mPR $\alpha$ axis, in the development and progression of TNBC. These observations suggest that, progesterone may be a potential target for the treatment of TNBCBM. $^{104}$

\section{Proteins}

ADAM8 is a transmembrane protein belonging to the "a disintegrin and metalloprotease" (ADAM) family. This protein is highly expressed in TNBC and derived metastases, and high ADAM8 levels predict poor prognosis. ADAM8 stimulates angiogenesis by releasing VEGF-A and promotes tumor cell proliferation by activating Integrin beta-1. Treatment with an anti-ADAM8 antibody could significantly reduce $\mathrm{CTC}$ numbers and BMs, suggesting that ADAM8 is a promising therapeutic target for TNBCBM treatment. ${ }^{105}$ Aldehyde dehydrogenase family 1 member A3 (ALDH1A3) is one of the representative proteins of EMT. ${ }^{106}$ A recent study identified ALDH1A3 as promoting $\mathrm{BM}$ development by regulating $\mathrm{CTC}$ adhesion and migration in the TNBCBM cascade. Knocking out ALDH1A3 has a selective inhibitory effect on BM, and dose not inhibit liver or bone metastasis. ${ }^{107}$ Gong et al found that inhibiting the expression of angiopoietin-like 4 (ANGPTL4), a secreted glycoprotein, in TNBC cells reduced metastatic growth in the brain. Furthermore, the secretion of transforming growth factor beta 2 (TGF- $\beta 2$ ) by astrocytes upregulated the expression of ANGPTL4 in TNBC cells. This finding suggests that the invading TNBC cells interact with astrocytes in the CNS microenvironment, and promotes BM through a TGF- $\beta 2 /$ ANGPTL4 axis. ${ }^{108}$ The increased expression of protocadherin 7 (PCDH7) in TNBC cells, induced through astrocyte interaction, has been reported to promote $\mathrm{BM}$ colonization. Furthermore, PCDH7 knockdown decreased metastatic lesion numbers and area sizes in the mouse brain. ${ }^{109}$ Dual-specificity phosphatase 6 (DUSP6) has been associated with breast cancer progression, recurrence, and metastasis. Wu et al found that, in TNBC patients, the DUSP6 protein was predominantly expressed in the nucleus of BM cells, but not in that of cells from lung or pleura metastasis; in contrast, DUSP6 was localized to the cytoplasm in primary tumor tissues. These results suggested that nuclear-localized DUSP6 expression may be associated with BM in TNBC patients, and thatDUSP6 peptide inhibitors may potentially reduce the risk of TNBC-related BM. ${ }^{110}$ The molecular chaperone $\alpha \mathrm{B}$-crystallin is highly expressed in TNBC and is associated with the promotion of an aggressive phenotype. Furthermore, $\alpha \mathrm{B}$-crystallin also has a role in promoting TNBC cell adhesion to BMECs, transendothelial migration, and $\mathrm{BBB}$ transmigration. The overexpression of $\alpha \mathrm{B}$-crystallin increases $\mathrm{BM}$ occurrence in an orthotopic 
TNBC model, whereas $\alpha \mathrm{B}$-crystallin silencing elicits the opposite effect. ${ }^{111}$

\section{Natural Products}

Gingerols are the main active components in ginger oleoresin. Martin et al reported that [10]-gingerol inhibits TNBC growth and spontaneous metastasis, especially that to the brain, by inducing caspase-dependent apoptosis. ${ }^{112}$ Cannabinoids derived from Cannabis sativa were shown to suppress TNBC growth in preclinical models. Furthermore, they could also inhibit tumor progression and invasion by reducing tumor angiogenesis, EGFR expression, and AKT phosphorylation, while also limiting the supply of nutrients and oxygen needed for tumor growth. ${ }^{113}$

\section{Potential Precision Anti-TNBCBM Therapy: Nanotechnology}

Although the BM-related BBB (the BTB) is structurally impaired and has greater permeability than healthy $\mathrm{BBB}$, it remains an important barrier to the delivery of drugs sites of to $\mathrm{BM} .^{51}$ In recent years, nanotechnology, has revolutionized how drugs are delivered and has unique advantages in the treatment of TNBCBM. Nanomaterials are used as carriers in chemotherapy, which can greatly improve the efficacy of conventional chemotherapy. They also allow drugs to freely cross the barriers of the body, such as the BBB, targeting drug delivery to specific lesions (such as BM). Additionally, through their high drug loading capacity, prolonged blood circulation time, capacity for sustained drug release, and potential for reduced enzyme-mediated drug degradation, nanomaterials can be used to maximize the benefits of treatment. ${ }^{114}$

Nanoparticles (NPs) loaded with doxorubicin (DOX), paclitaxel (PTX), or docetaxel (DTX) as therapeutic agents are currently the most studied formulations for treating metastatic breast cancer. Metastatic TNBC can be specifically targeted and treated with NPs that carry single or multiple therapeutic agents. ${ }^{115} \mathrm{He}$ et al developed an amphiphilic polymer-lipid nanocarrier system that could deliver DTX to TNBCBMs. Compared with an equivalent dose of a clinical preparation of DTX, DTX-NPs showed rapid uptake by TNBC cells, elevated intracellular drug concentrations, prolonged drug circulation time, and increased brain bioavailability, which significantly inhibited $\mathrm{BM}$ growth and prolonged the survival time of patients. Importantly, these effects were not accompanied by histological changes in the main organs, including the lungs, liver, kidneys, and heart. ${ }^{116} \mathrm{Li}$ et al constructed a PTX-loaded liposome co-modified with acid-cleavable folic acid (FA) and the BBB-transmigrating, cellpenetrating dNP2 peptide (cFd-Lip/PTX) to synergically improve BBB penetration and the targeting of the tumor microenvironment (TME). The authors found that cFd-Lip was the sensitive to cleavage in the acidic TME, which maximized the function of both FA and the dNP2 peptide. This liposome allowed for deeper penetration and increased accumulation in primary breast cancer and sites of BM, thus helping to enhance anti-tumor activity. This cascade targeting strategy provides a feasible method for overcoming the TME and the BBB in primary breast cancer and associated $\mathrm{BM}^{117}$ Zhang et al designed a multitarget drug delivery system consisting of a cyclic internalizing peptide (iRGD)-modified terpolymer-lipid hybrid nanoparticle system (TPLN) coloaded with DOX and mitomycin C (MMC) (iRGD-DMTPLN). Compared with untargeted DMTPLN or a free DOX/MMC combination, iRGD-DMTPLN treatment reduced the TNBCBM by 6-fold and 19-fold, respectively, and prolonged host median survival by 1.3 -fold and 1.6-fold, respectively. Meanwhile, this nanosystem also reduced the cardiotoxicity associated with the DOX/MMC combination. ${ }^{118}$

Because many nanocarriers and targeting moieties can bind nonspecifically to tumor cells, as well as to extracellular and intravascular components, developing effective nano-drug preparations targeting tumor cells has always been challenging. The recently developed "DART" nanoparticles could effectively ameliorate this problem. PTX-DART nanoparticles could directly bind to fibroblast growth factorinducible 14 (Fn14) that is highly expressed on the surface of TNBC cells in both primary TNBC and associated BM, and released a high concentration of PTX to kill the cancer cells while reducing the killing of normal cells. ${ }^{119}$

Nanotechnology has brought new opportunities for antiTNBCBM precision therapy. The development of precision medicine, in combination with an in-depth understanding of TNBCBM-specific markers, will allow for more accurate identification of tumor proliferation and metastatic-related signaling pathways and the discovery of drug targets in CSCs. Novel TNBCBM drug delivery systems, which integrate nanotechnology and precision therapy, hold promise as a means of blocking BM occurrence and development.

\section{Conclusion}

$\mathrm{BM}$ is one of the main complications associated with TNBC and the most severe event threatening the survival 
of TNBC patients. However, there is no FDA-approved drug currently available for the treatment of TNBCBM. Consequently, there is a need for a comprehensive understanding of the biology of TNBCBM to allow the development new therapies. The unique biological characteristics of TNBC cells are conducive to brain invasion and metastasis, and the destruction of the BBB, the formation of highly permeable BTB, and changes in the CNS microenvironment all play a key role in the formation of TNBCBM. Although newly identified therapeutic targets and novel strategies have brought new hope to BM patients, more research is required to allow the development of effective and low-toxicity treatment regimens for TNBCBM patients. Future research directions may include (i) further investigation of the mechanisms underlying the development of TNBCBM, such as lipid metabolism in metastatic cells in the brain, BM-specific gene mutations, and changes in gene expression; (ii) developing novel therapeutic agents that can adequately penetrate the BBB and target the main steps of the metastatic cascade; (iii) conducting preclinical and clinical studies of targeted drugs to explore their mechanism-of-action, efficacy, and appropriate doses; (iv) identifying the high-risk factors for $\mathrm{BM}$ in TNBC patients and developing risk prediction tools. The emergence of modern precision medicine, indepth knowledge of the biological behavior of TNBCBM and related signaling pathways, the selection of more accurate targeted therapies, and the development of more clinical trials, may in the future, lead to more precise and individualized treatment options for TNBCBM patients.

\section{Acknowledgments}

No applicable.

\section{Author Contributions}

All authors made substantial contributions to conception and design, acquisition of data, or analysis and interpretation of data; took part in drafting the article or revising it critically for important intellectual content; agreed to submit to the current journal; gave final approval of the version to be published; and agree to be accountable for all aspects of the work.

\section{Funding}

This research was supported by grants from Jiangsu Provincial Key Discipline of Medicine (grant no. ZDXKA2016009 to J.F.).

\section{Disclosure}

The authors report no conflicts of interest in this work.

\section{References}

1. Siegel RL, Miller KD, Jemal A. Cancer Statistics 2017. CaCancer J Clin. 2017;67(1):7-30. doi:10.3322/caac.21387

2. Anders C, Carey LA. Understanding and treating triple-negative breast cancer. Oncology (Williston Park). 2008;22(11):1233-1239; discussion 1239-1240, 1243.

3. Li XX, Yang J, Peng LM, et al. Triple-negative breast cancer has worse overall survival and cause-specific survival than non-triplenegative breast cancer. Breast Cancer Res Tr. 2017;161 (2):279-287. doi:10.1007/s10549-016-4059-6

4. Al-Mahmood S, Sapiezynski J, Garbuzenko OB, Minko T. Metastatic and triple-negative breast cancer: challenges and treatment options. Drug Deliv Transl Res. 2018;8(5):1483-1507.

5. Brosnan EM, Anders CK. Understanding patterns of brain metastasis in breast cancer and designing rational therapeutic strategies. Ann Transl Med. 2018;6(9):163. doi:10.21037/atm.2018.04.35

6. Ostrom QT, Wright CH, Barnholtz-Sloan JS. Brain metastases: epidemiology. Handb Clin Neurol. 2018;149:27-42.

7. Wanleenuwat P, Iwanowski P. Metastases to the central nervous system: molecular basis and clinical considerations. J Neurol Sci. 2020;412:116755. doi:10.1016/j.jns.2020.116755

8. Lin NU, Claus E, Sohl J, Razzak AR, Arnaout A, Winer EP. Sites of distant recurrence and clinical outcomes in patients with metastatic triple-negative breast cancer: high incidence of central nervous system metastases. Cancer. 2008;113(10):2638-2645. doi:10.1002/cner.23930

9. Martin AM, Cagney DN, Catalano PJ, et al. Brain metastases in newly diagnosed breast cancer a population-based study. JAMA Oncol. 2017;3(8):1069-1077. doi:10.1001/ jamaoncol.2017.0001

10. Kim YJ, Kim JS, Kim IA. Molecular subtype predicts incidence and prognosis of brain metastasis from breast cancer in SEER database. $J$ Cancer Res Clin. 2018;144(9):1803-1816. doi:10.1007/s00432-018-2697-2

11. Duchnowska R, Jarzab M, Zebracka-Gala J, et al. Brain metastasis prediction by transcriptomic profiling in triple-negative breast cancer. Clin Breast Cancer. 2017;17(2):E65-E75. doi:10.1016/j.clbc.2016.08.008

12. Yao Y, Chu Y, Xu B, Hu Q, Song Q. Risk factors for distant metastasis of patients with primary triple-negative breast cancer. Biosci Rep. 2019;39:6. doi:10.1042/BSR20190288

13. Kaidar-Person O, Meattini I, Jain P, et al. Discrepancies between biomarkers of primary breast cancer and subsequent brain metastases: an international multicenter study. Breast Cancer Res Tr. 2018;167(2):479-483. doi:10.1007/s10549-017-4526-8

14. Wang Z, Zhang X, Shen P, Loggie BW, Chang Y, Deuel TF. Identification, cloning, and expression of human estrogen receptor-alpha36, a novel variant of human estrogen receptor-alpha66. Biochem Biophys Res Commun. 2005;336 (4):1023-1027. doi:10.1016/j.bbrc.2005.08.226

15. Wang Z, Zhang X, Shen P, Loggie BW, Chang Y, Deuel TF. A variant of estrogen receptor- $\{$ alpha $\}$, hER-\{alpha\}36: transduction of estrogen- and antiestrogen-dependent membrane-initiated mitogenic signaling. Proc Natl Acad Sci $U \quad S \quad$ A. 2006;103(24):9063-9068. doi:10.1073/pnas.060 3339103

16. Zhang XT, Kang LG, Ding L, Vranic S, Gatalica Z, Wang ZY. A positive feedback loop of ER-alpha36/EGFR promotes malignant growth of ER-negative breast cancer cells. Oncogene. 2011;30(7):770-780. doi:10.1038/onc.2010.458 
17. Zhang X, Meng J, Wang ZY. A switch role of Src in the biphasic EGF signaling of ER-negative breast cancer cells. PLoS One. 2012;7(8):e41613. doi:10.1371/journal.pone.0041613

18. Zhang XT, Ding L, Kang LG, Wang ZY. Involvement of ER-alpha36, Src, EGFR and STAT5 in the biphasic estrogen signaling of ER-negative breast cancer cells. Oncol Rep. 2012;27(6):2057-2065. doi:10.3892/or.2012.1722

19. Ma F, Li H, Wang H, et al. Enriched CD44(+)/CD24(-) population drives the aggressive phenotypes presented in triple-negative breast cancer (TNBC). Cancer Lett. 2014;353(2):153-159. doi:10.1016/j.canlet.2014.06.022

20. Li H, Ma F, Wang H, et al. Stem cell marker aldehyde dehydrogenase 1 (ALDH1)-expressing cells are enriched in triple-negative breast cancer. Int J Biol Markers. 2013;28(4): e357-364. doi:10.5301/JBM.5000048

21. Li W, Ma H, Zhang J, Zhu L, Wang C, Yang Y. Unraveling the roles of CD44/CD24 and ALDH1 as cancer stem cell markers in tumorigenesis and metastasis. Sci Rep. 2017;7(1):13856. doi:10.1038/s41598-017-14364-2

22. Liu P, Tang H, Song C, et al. SOX2 promotes cell proliferation and metastasis in triple negative breast cancer. Front Pharmacol. 2018;9:942. doi:10.3389/fphar.2018.00942

23. Horiuchi D, Kusdra L, Huskey NE, et al. MYC pathway activation in triple-negative breast cancer is synthetic lethal with CDK inhibition. J Exp Med. 2012;209(4):679-696. doi:10.1084/jem.20111512

24. Park SY, Choi JH, Nam JS. Targeting cancer stem cells in triple-negative breast cancer. Cancers (Basel). 2019;11:7. doi:10.3390/cancers11070965

25. Yang J, Mani SA, Donaher JL, et al. Twist, a master regulator of morphogenesis, plays an essential role in tumor metastasis. Cell. 2004;117(7):927-939. doi:10.1016/j.cell.2004.06.006

26. Yu M, Bardia A, Wittner B, et al. Circulating breast tumor cells exhibit dynamic changes in epithelial and mesenchymal composition. Science. 2013;339(6119):580-584. doi:10.1126/ science. 1228522

27. Fischer KR, Altorki NK, Mittal V, Gao DC. Upholding a role for EMT in breast cancer metastasis Reply. Nature. 2017;547(7661): E5-E6. doi:10.1038/nature22817

28. Chaffer CL, Marjanovic ND, Lee T, et al. Poised Chromatin at the ZEB1 promoter enables breast cancer cell plasticity and enhances tumorigenicity. Cell. 2013;154(1):61-74. doi:10.1016/j. cell.2013.06.005

29. Karihtala P, Auvinen P, Kauppila S, Haapasaari KM, JukkolaVuorinen A, Soini Y. Vimentin, zeb1 and Sip1 are up-regulated in triple-negative and basal-like breast cancers: association with an aggressive tumour phenotype. Breast Cancer Res Tr. 2013;138 (1):81-90. doi:10.1007/s10549-013-2442-0

30. Liu T, Zhang XY, Shang M, et al. Dysregulated expression of Slug, vimentin, and E-cadherin correlates with poor clinical outcome in patients with basal-like breast cancer. J Surg Oncol. 2013;107(2):188-194. doi:10.1002/jso.23240

31. Yamashita N, Tokunaga E, Kitao $\mathrm{H}$, et al. Vimentin as a poor prognostic factor for triple-negative breast cancer. $J$ Cancer Res Clin. 2013;139(5):739-746. doi:10.1007/s00432-013-1376-6

32. Khaled N, Bidet Y. New insights into the implication of epigenetic alterations in the EMT of triple negative breast cancer. Cancers. 2019;11:4. doi:10.3390/cancers11040559

33. Bowers LW, Rossi EL, McDonell SB, et al. Leptin signaling mediates obesity-associated CSC enrichment and EMT in preclinical TNBC models. Mol Cancer Res. 2018;16(5):869-879. doi:10.1158/1541-7786.MCR-17-0508

34. Nalla LV, Kalia K, Khairnar A. Self-renewal signaling pathways in breast cancer stem cells. Int $J$ Biochem Cell $B$. 2019;107:140-153. doi:10.1016/j.biocel.2018.12.017
35. Minakshi R, Rahman S, Jan AT, Archana A, Kim J. Implications of aging and the endoplasmic reticulum unfolded protein response on the molecular modality of breast cancer. Exp Mol Med. 2017;49(11):49. doi:10.1038/emm.2017.215

36. Mittal D, Sinha D, Barkauskas D, et al. Adenosine 2B receptor expression on cancer cells promotes metastasis. Cancer Res. 2016;76(15):4372-4382. doi:10.1158/0008-5472.CAN-16-0544

37. Fabbri F, Salvi S, Bravaccini S. Know your enemy: genetics, aging, exposomic and inflammation in the war against triple negative breast cancer. Semin Cancer Biol. 2019;60:285-293. doi:10.1016/j.semcancer.2019.10.015

38. Abbott NJ, Patabendige AAK, Dolman DEM, Yusof SR, Begley DJ. Structure and function of the blood-brain barrier. Neurobiol Dis. 2010;37(1):13-25. doi:10.1016/j.nbd.2009.07.030

39. Villasenor R, Lampe J, Schwaninger M, Collin L. Intracellular transport and regulation of transcytosis across the blood-brain barrier. Cell Mol Life Sci. 2019;76(6):1081-1092. doi:10.1007/ s00018-018-2982-x

40. Wilhelm I, Molnar J, Fazakas C, Hasko J, Krizbai IA. Role of the blood-brain barrier in the formation of brain metastases. Int $\mathrm{J} \mathrm{Mol}$ Sci. 2013;14(1):1383-1411. doi:10.3390/ijms14011383

41. Mills MN, Figura NB, Arrington JA, et al. Management of brain metastases in breast cancer: a review of current practices and emerging treatments. Breast Cancer Res Treat. 2020;180 (2):279-300. doi:10.1007/s10549-020-05552-2

42. Kienast Y, von Baumgarten L, Fuhrmann M, et al. Real-time imaging reveals the single steps of brain metastasis formation. Nat Med. 2010;16(1):116-U157. doi:10.1038/nm.2072

43. Blecharz KG, Colla R, Rohde V, Vajkoczy P. Control of the blood-brain barrier function in cancer cell metastasis. Biol Cell. 2015;107(10):342-371.

44. Avraham HK, Jiang SX, Fu YG, Nakshatri H, Ovadia H, Avraham S. Angiopoietin-2 mediates blood-brain barrier impairment and colonization of triple-negative breast cancer cells in brain. J Pathol. 2014;232(3):369-381. doi:10.1002/path.4304

45. Yonemori K, Tsuta K, Ono M, et al. Disruption of the blood brain barrier by brain metastases of triple-negative and basal-type breast cancer but not HER2/neu-Positive Breast Cancer. Cancer. 2010;116(2):302-308. doi:10.1002/cncr.24735

46. Mustafa DAM, Pedrosa RMSM, Smid M, et al. T lymphocytes facilitate brain metastasis of breast cancer by inducing Guanylate-Binding Protein 1 expression. Acta Neuropathol. 2018;135(4):581-599. doi:10.1007/s00401-018-1806-2

47. Pedersen MH, Hood BL, Beck HC, Conrads TP, Ditzel HJ, LethLarsen R. Downregulation of antigen presentation-associated pathway proteins is linked to poor outcome in triple-negative breast cancer patient tumors. Oncoimmunology. 2017;6:5. doi:10.1080/2162402X.2017.1305531

48. Logsdon AF, Erickson MA, Rhea EM, Salameh TS, Banks WA. Gut reactions: how the blood-brain barrier connects the microbiome and the brain. Exp Biol Med. 2018;243(2):159-165. doi:10.1177/1535370217743766

49. Liebner S, Dijkhuizen RM, Reiss Y, Plate KH, Agalliu D, Constantin G. Functional morphology of the blood-brain barrier in health and disease. Acta Neuropathol. 2018;135(3):311-336. doi:10.1007/s00401-018-1815-1

50. Arvanitis CD, Askoxylakis V, Guo YT, et al. Mechanisms of enhanced drug delivery in brain metastases with focused ultrasound-induced blood-tumor barrier disruption. P Natl Acad Sci USA. 2018;115(37):E8717-E8726.

51. Lockman PR, Mittapalli RK, Taskar KS, et al. Heterogeneous blood-tumor barrier permeability determines drug efficacy in experimental brain metastases of breast cancer. Clin Cancer Res. 2010;16(23):5664-5678. doi:10.1158/1078-0432.CCR-101564 
52. Lyle LT, Lockman PR, Adkins CE, et al. Alterations in pericyte subpopulations are associated with elevated blood-tumor barrier permeability in experimental brain metastasis of breast cancer. Clin Cancer Res. 2016;22(21):5287-5299. doi:10.1158/10780432.CCR-15-1836

53. Shah N, Mohammad AS, Saralkar P, et al. Investigational chemotherapy and novel pharmacokinetic mechanisms for the treatment of breast cancer brain metastases. Pharmacol Res. 2018;132:47-68. doi:10.1016/j.phrs.2018.03.021

54. Echeverria GV, Powell E, Seth S, et al. High-resolution clonal mapping of multi-organ metastasis in triple negative breast cancer. Nat Commun. 2018;9(1):5079. doi:10.1038/s41467-01807406-4

55. Siegel MB, He X, Hoadley KA, et al. Integrated RNA and DNA sequencing reveals early drivers of metastatic breast cancer. J Clin Invest. 2018;128(4):1371-1383. doi:10.1172/JCI96153

56. Zhang H, Zhang N, Liu Y, et al. Epigenetic Regulation of NAMPT by NAMPT-AS drives metastatic progression in triple-negative breast cancer. Cancer Res. 2019;79 (13):3347-3359. doi:10.1158/0008-5472.CAN-18-3418

57. Zhang N, Zhang H, Liu Y, et al. SREBP1, targeted by miR-18a$5 \mathrm{p}$, modulates epithelial-mesenchymal transition in breast cancer via forming a co-repressor complex with Snail and HDAC1/2. Cell Death Differ. 2019;26(5):843-859. doi:10.1038/s41418-0180158-8

58. Liang Y, Hu J, Li J, et al. Epigenetic Activation of TWIST1 by MTDH promotes cancer stem-like cell traits in breast cancer. Cancer Res. 2015;75(17):3672-3680. doi:10.1158/0008-5472. CAN-15-0930

59. Riebensahm C, Joosse SA, Mohme M, et al. Clonality of circulating tumor cells in breast cancer brain metastasis patients. Breast Cancer Res. 2019;21(1):101. doi:10.1186/s13058-019-1184-2

60. Chandler RL, Damrauer JS, Raab JR, et al. Coexistent ARID1A-PIK3CA mutations promote ovarian clear-cell tumorigenesis through pro-tumorigenic inflammatory cytokine signalling. Nat Commun. 2015;6:6118. doi:10.1038/ncomms7118

61. Qian J, Chen H, Ji X, et al. A 3q gene signature associated with triple negative breast cancer organ specific metastasis and response to neoadjuvant chemotherapy. Sci Rep. 2017;7:45828. doi:10.1038/srep45828

62. Yomtoubian S, Lee SB, Verma A, et al. Inhibition of EZH2 catalytic activity selectively targets a metastatic subpopulation in triple-negative breast cancer. Cell Rep. 2020;30(3):755770e756. doi:10.1016/j.celrep.2019.12.056

63. Peluffo G, Subedee A, Harper NW, et al. EN1 is a transcriptional dependency in triple-negative breast cancer associated with brain metastasis. Cancer Res. 2019;79(16):4173-4183. doi:10.1158/ 0008-5472.CAN-18-3264

64. Luzzi KJ, MacDonald IC, Schmidt EE, et al. Multistep nature of metastatic inefficiency - Dormancy of solitary cells after successful extravasation and limited survival of early micrometastases. Am J Pathol. 1998;153(3):865-873. doi:10.1016/S0002-9440(10) 65628-3

65. Paget S. The distribution of secondary growths in cancer of the breast. 1889. Cancer Metastasis Rev. 1989;8(2):98-101.

66. Liu Q, Zhang HF, Jiang XL, Qian CY, Liu ZQ, Luo DY. Factors involved in cancer metastasis: a better understanding to "seed and soil" hypothesis. Mol Cancer. 2017;16.

67. Witzel I, Laakmann E, Weide R, et al. Treatment and outcomes of patients in the Brain Metastases in Breast Cancer Network Registry. Eur J Cancer. 2018;102:1-9. doi:10.1016/j. ejca.2018.07.004

68. Carbonell WS, Ansorge O, Sibson N, Muschel R. The Vascular Basement Membrane as "Soil" in Brain Metastasis. PLoS One. 2009;4:6. doi:10.1371/journal.pone.0005857
69. de Palma M, Biziato D, Petrova TV. Microenvironmental regulation of tumour angiogenesis. Nat Rev Cancer. 2017;17 (8):457-474. doi:10.1038/nrc.2017.51

70. Gunasinghe NP, Wells A, Thompson EW, Hugo HJ. Mesenchymal-epithelial transition (MET) as a mechanism for metastatic colonisation in breast cancer. Cancer Metastasis Rev. 2012;31(3-4):469-478. doi:10.1007/s10555-012-9377-5

71. Zhang L, Zhang S, Yao J, et al. Microenvironment-induced PTEN loss by exosomal microRNA primes brain metastasis outgrowth. Nature. 2015;527(7576):100-104. doi:10.1038/nature15376

72. Hohensee I, Chuang HN, Grottke A, et al. PTEN mediates the cross talk between breast and glial cells in brain metastases leading to rapid disease progression. Oncotarget. 2017;8 (4):6155-6168. doi:10.18632/oncotarget.14047

73. Rippaus N, Taggart D, Williams J, et al. Metastatic site-specific polarization of macrophages in intracranial breast cancer metastases. Oncotarget. 2016;7(27):41473-41487. doi:10.18632/oncotarget.9445

74. Neman J, Termini J, Wilczynski S, et al. Human breast cancer metastases to the brain display GABAergic properties in the neural niche. P Natl Acad Sci USA. 2014;111(3):984-989. doi:10.1073/pnas.1322098111

75. Lee M, Heo SH, Song IH, et al. Presence of tertiary lymphoid structures determines the level of tumor-infiltrating lymphocytes in primary breast cancer and metastasis. Mod Pathol. 2019;32 (1):70-80. doi:10.1038/s41379-018-0113-8

76. Zhu L, Narloch JL, Onkar S, et al. Metastatic breast cancers have reduced immune cell recruitment but harbor increased macrophages relative to their matched primary tumors. J Immunother Cancer. 2019;7(1):265. doi:10.1186/s40425-019-0755-1

77. Sambade MJ, Prince G, Deal AM, et al. Examination and prognostic implications of the unique microenvironment of breast cancer brain metastases. Breast Cancer Res Treat. 2019;176 (2):321-328. doi:10.1007/s10549-019-05211-1

78. Kuo MH, Chang WW, Yeh BW, et al. 3 is essential for the survival of breast cancer cells in the brain. Cells. 2019;8:12. doi: $10.3390 /$ cells 8121568

79. Dong T, Liu Z, Xuan Q, Wang Z, Ma W, Tumor ZQ. LDH-A expression and serum LDH status are two metabolic predictors for triple negative breast cancer brain metastasis. Sci Rep. 2017;7 (1):6069. doi:10.1038/s41598-017-06378-7

80. Proteomic Analysis of the Breast Cancer Brain Metastasis Microenvironment. 2019;20:10

81. Ciminera AK, Jandial R, Termini J. Metabolic advantages and vulnerabilities in brain metastases. Clin Exp Metastasis. 2017;34 (6-7):401-410. doi:10.1007/s10585-017-9864-8

82. Choi J, Kim DH, Jung WH, Koo JS. Metabolic interaction between cancer cells and stromal cells according to breast cancer molecular subtype. Breast Cancer Res. 2013;15(5):R78. doi:10.1186/bcr3472

83. Contreras-Zarate MJ, Day NL, Ormond DR, et al. Estradiol induces $\mathrm{BDNF} / \mathrm{TrkB}$ signaling in triple-negative breast cancer to promote brain metastases. Oncogene. 2019;38(24):4685-4699. doi:10.1038/s41388-019-0756-Z

84. Costa R, Gill N, Rademaker AW, et al. Systematic analysis of early phase clinical studies for patients with breast cancer: inclusion of patients with brain metastasis. Cancer Treat Rev. 2017;55:10-15. doi:10.1016/j.ctrv.2017.02.006

85. Papadimitriou M, Mountzios G, Papadimitriou CA. The role of PARP inhibition in triple-negative breast cancer: unraveling the wide spectrum of synthetic lethality. Cancer Treat Rev. 2018;67:34-44. doi:10.1016/j.ctrv.2018.04.010

86. Karginova O, Siegel MB, Van Swearingen AE, et al. Efficacy of Carboplatin Alone and in Combination with ABT888 in Intracranial Murine Models of BRCA-Mutated and BRCA-WildType Triple-Negative Breast Cancer. Mol Cancer Ther. 2015;14 (4):920-930. doi:10.1158/1535-7163.MCT-14-0474 
87. Litton JK, Rugo HS, Ettl J, et al. Talazoparib in Patients with Advanced Breast Cancer and a Germline BRCA Mutation. N Engl $J$ Med. 2018;379(8):753-763. doi:10.1056/NEJMoa1802905

88. Turner NC, Telli ML, Rugo HS, et al. A Phase II Study of Talazoparib after Platinum or Cytotoxic Nonplatinum Regimens in Patients with Advanced Breast Cancer and Germline BRCA1/2 Mutations (ABRAZO). Clin Cancer Res. 2019;25(9):2717-2724. doi:10.1158/1078-0432.CCR-18-1891

89. Anders C, Deal AM, Abramson V, et al. TBCRC 018: phase II study of iniparib in combination with irinotecan to treat progressive triple negative breast cancer brain metastases. Breast Cancer Res Treat. 2014;146(3):557-566. doi:10.1007/s10549-014-3039-y

90. Lu YS, Chen TW, Lin CH, et al. Bevacizumab preconditioning followed by Etoposide and Cisplatin is highly effective in treating brain metastases of breast cancer progressing from whole-brain radiotherapy. Clin Cancer Res. 2015;21(8):1851-1858. doi:10.1158/1078-0432.CCR-14-2075

91. Saleh R, Taha RZ, Sasidharan Nair V, Alajez NM, Elkord E. PDL1 Blockade by atezolizumab downregulates signaling pathways associated with tumor growth, metastasis, and hypoxia in human triple negative breast cancer. Cancers (Basel). 2019;11:8. doi:10.3390/cancers 11081050

92. Duchnowska R, Peksa R, Radecka B, et al. Immune response in breast cancer brain metastases and their microenvironment: the role of the PD-1/PD-L axis. Breast Cancer Res. 2016;18(1):43. doi:10.1186/s13058-016-0702-8

93. Schmid P, Adams S, Rugo HS, et al. Atezolizumab and Nab-Paclitaxel in advanced triple-negative breast cancer. $N$ Engl $J$ Med. 2018;379(22):2108-2121. doi:10.1056/NEJMoa1809615

94. Kanchan RK, Siddiqui JA, Mahapatra S, Batra SK, Nasser MW. microRNAs orchestrate pathophysiology of breast cancer brain metastasis: advances in therapy. Mol Cancer. 2020;19(1):29. doi:10.1186/s12943-020-1140-x

95. Debeb BG, Lacerda L, Anfossi S, et al. miR-141-mediated regulation of brain metastasis from breast cancer. $J$ Natl Cancer Inst. 2016;108:8. doi:10.1093/jnci/djw026

96. Fong MY, Zhou W, Liu L, et al. Breast-cancer-secreted miR-122 reprograms glucose metabolism in premetastatic niche to promote metastasis. Nat Cell Biol. 2015;17(2):183-194. doi:10.1038/ ncb3094

97. Xing F, Sharma S, Liu Y, et al. miR-509 suppresses brain metastasis of breast cancer cells by modulating RhoC and TNF-alpha. Oncogene. 2015;34(37):4890-4900. doi:10.1038/onc.2014.412

98. Okuda H, Xing F, Pandey PR, et al. miR-7 suppresses brain metastasis of breast cancer stem-like cells by modulating KLF4. Cancer Res. 2013;73(4):1434-1444. doi:10.1158/0008-5472. CAN-12-2037

99. Ahmad A, Ginnebaugh KR, Sethi $S$, et al. miR-20b is up-regulated in brain metastases from primary breast cancers. Oncotarget. 2015;6(14):12188-12195. doi:10.18632/ oncotarget.3664

100. Sereno M, Hasko J, Molnar K, et al. Downregulation of circulating miR $802-5 p$ and $\mathrm{miR} 194-5 \mathrm{p}$ and upregulation of brain MEF2C along breast cancer brain metastasization. Mol Oncol. 2020;14(3):520-538. doi:10.1002/1878-0261.12632

101. Xing F, Liu Y, Wu SY, et al. Loss of XIST in Breast Cancer Activates MSN-c-Met and reprograms microglia via exosomal miRNA to promote brain metastasis. Cancer Res. 2018;78 (15):4316-4330. doi:10.1158/0008-5472.CAN-18-1102

102. Wang S, Liang $\mathrm{K}, \mathrm{Hu} \mathrm{Q}$, et al. JAK2-binding long noncoding RNA promotes breast cancer brain metastasis. $J$ Clin Invest. 2017;127(12):4498-4515. doi:10.1172/JCI91553

103. Fu B, Zhang A, Li M, et al. Circular RNA profile of breast cancer brain metastasis: identification of potential biomarkers and therapeutic targets. Epigenomics. 2018;10(12):1619-1630. doi:10.2217/epi-2018-0090
104. Zhou L, Zhou W, Zhang H, et al. Progesterone suppresses triple-negative breast cancer growth and metastasis to the brain via membrane progesterone receptor alpha. Int $J$ Mol Med. 2017;40(3):755-761. doi:10.3892/ijmm.2017.3060

105. Romagnoli M, Mineva ND, Polmear M, et al. ADAM8 expression in invasive breast cancer promotes tumor dissemination and metastasis. EMBO Mol Med. 2014;6(2):278-294. doi:10.1002/ emmm. 201303373

106. Marcato P, Dean CA, Liu RZ, et al. Aldehyde dehydrogenase 1A3 influences breast cancer progression via differential retinoic acid signaling. Mol Oncol. 2015;9(1):17-31. doi:10.1016/j. molonc.2014.07.010

107. Yamashita D, Minata M, Ibrahim AN, et al. Identification of ALDH1A3 as a viable therapeutic target in breast cancer metastasis-initiating cells. Mol Cancer Ther. 2020;19 (5):1134-1147. doi:10.1158/1535-7163.MCT-19-0461

108. Gong X, Hou Z, Endsley MP, et al. Interaction of tumor cells and astrocytes promotes breast cancer brain metastases through TGF-beta2/ANGPTL4 axes. NPJ Precis Oncol. 2019;3:24. doi:10.1038/s41698-019-0094-1

109. Ren D, Zhu X, Kong R, et al. Targeting brain-adaptive cancer stem cells prohibits brain metastatic colonization of triple-negative breast cancer. Cancer Res. 2018;78 (8):2052-2064. doi:10.1158/0008-5472.CAN-17-2994

110. Wu F, McCuaig RD, Sutton CR, et al. Nuclear-Biased DUSP6 expression is associated with cancer spreading including brain metastasis in triple-negative breast cancer. Int $\mathrm{J}$ Mol Sci. 2019;20:12.

111. Malin D, Strekalova E, Petrovic V, et al. alphaB-crystallin: a novel regulator of breast cancer metastasis to the brain. Clin Cancer Res. 2014;20(1):56-67. doi:10.1158/1078-0432.CCR-131255

112. Martin A, Fuzer AM, Becceneri AB, da Silva JA, Tomasin R, Denoyer D. [10]-gingerol induces apoptosis and inhibits metastatic dissemination of triple negative breast cancer in vivo. 2017;8(42):72260-72271. doi:10.18632/oncotarget.20139

113. Kiskova T, Mungenast F, Suvakova M, Jager W, Thalhammer T. Future aspects for cannabinoids in breast cancer therapy. Int J Mol Sci. 2019;20:7. doi:10.3390/ijms20071673

114. Wong HL, Wu XY, Bendayan R. Nanotechnological advances for the delivery of CNS therapeutics. Adv Drug Deliv Rev. 2012;64 (7):686-700. doi:10.1016/j.addr.2011.10.007

115. Miller-Kleinhenz JM, Bozeman EN, Yang L. Targeted nanoparticles for image-guided treatment of triple-negative breast cancer: clinical significance and technological advances. Wiley Interdiscip Rev Nanomed Nanobiotechnol. 2015;7(6):797-816. doi:10.1002/ wnan. 1343

116. He C, Cai P, Li J, et al. Blood-brain barrier-penetrating amphiphilic polymer nanoparticles deliver docetaxel for the treatment of brain metastases of triple negative breast cancer. $J$ Control Release. 2017;246:98-109. doi:10.1016/j.jconrel.2016.12.019

117. Li M, Shi K, Tang X, et al. Synergistic tumor microenvironment targeting and blood-brain barrier penetration via a $\mathrm{pH}$-responsive dual-ligand strategy for enhanced breast cancer and brain metastasis therapy. Nanomedicine. 2018;14(6):1833-1843. doi:10.1016/j.nano.2018.05.008

118. Zhang T, Lip H, He C, et al. Multitargeted nanoparticles deliver synergistic drugs across the blood-brain barrier to brain metastases of triple negative breast cancer cells and tumor-associated macrophages. Adv Healthc Mater. 2019;8(18):e1900543. doi:10.1002/adhm.201900543

119. Dancy JG, Wadajkar AS, Connolly NP, et al. Decreased nonspecific adhesivity, receptor-targeted therapeutic nanoparticles for primary and metastatic breast cancer. Sci Adv. 2020;6(3): eaax3931. doi:10.1126/sciadv.aax3931 


\section{Publish your work in this journal}

OncoTargets and Therapy is an international, peer-reviewed, open access journal focusing on the pathological basis of all cancers, potential targets for therapy and treatment protocols employed to improve the management of cancer patients. The journal also focuses on the impact of management programs and new therapeutic

Submit your manuscript here: https://www.dovepress.com/oncotargets-and-therapy-journal agents and protocols on patient perspectives such as quality of life, adherence and satisfaction. The manuscript management system is completely online and includes a very quick and fair peer-review system, which is all easy to use. Visit http://www.dovepress.com/ testimonials.php to read real quotes from published authors. 